\title{
EL PAPEL DE LAS AUTORIDADES TERRITORIALES EN LA DEFINICIÓN DE ZONAS DE EXCLUSIÓN O RESTRICCIÓN MINERA*
}

\section{THE ROLE OF TERRITORIAL AUTHORITIES IN THE DEFINITION OF MINING RESTRICTION OR EXCLUSION ZONES}

\author{
Leonardo Güiza-Suarez** \\ Cristhian Rodríguez-Barajas *** \\ Fecha de recepción: 2 de septiembre de 2014 \\ Fecha de aceptación: 17 de julio de 2015 \\ Disponible en línea: 30 de noviembre de 2015
}

\section{Para citar este artículo/To cite this article}

Güiza, Leonardo \& Rodríguez, Cristhian, El papel de las autoridades territoriales en la definición de zonas de exclusión o restricción minera, 131 Vniversitas, 323-362 (2015). http://dx.doi.org/10.11144/Javeriana.vj131.patd doi:10.11144/Javeriana.vj131.patd

* El presente artículo de reflexión es el producto del trabajo adelantado por el Grupo de Investigación en Derechos Humanos de la Facultad de Jurisprudencia de la Universidad del Rosario.

** Abogado, biólogo, MSc en derechos humanos, Universidad de Alcalá (España), MSc en derecho industrial, Universidad de Poitiers (Francia). Profesor de carrera académica, Facultad de Jurisprudencia, Universidad del Rosario (Colombia). Grupo de Investigación en Derechos Humanos (Categoría A, Colciencias). Contacto: leonardo.guiza@urosario.edu.co.

*** Abogado especializado en derecho ambiental, Universidad del Rosario. Asistente de investigación del Grupo de Investigación en Derechos Humanos. Contacto: rodriguezb.cristhian@ urosario.edu.co 


\section{RESUMEN}

El desarrollo de la actividad minera genera tensiones entre los intereses del nivel central del Estado y las entidades territoriales locales sobre las que recaen las consecuencias ambientales, sociales y culturales de la extracción. Esto ha traído un debate jurídico sobre la prevalencia entre los principios del Estado unitario y la utilidad pública e interés social de la industria minera de una parte y, de otra, la autonomía territorial y la utilidad pública e interés social del medio ambiente. Este artículo de reflexión esclarece el papel que desempeñan las entidades territoriales en la adopción de decisiones relacionadas con la actividad minera, a partir del análisis de los desarrollos reglamentarios, legales, constitucionales y jurisprudenciales sobre la materia. Esto evidencia que las autoridades territoriales cuentan con varias herramientas jurídicas que les permiten y en algunos casos les imponen el deber de participar de manera activa y eficaz en la adopción de autorizaciones para llevar a cabo las actividades mineras en su jurisdicción, lo cual se ajusta con los principios de coordinación, concurrencia y subsidiariedad.

Palabras clave: municipios; minería; participación; ambiente; consulta popular; Colombia 


\section{ABSTRACT}

The development of mining activities generates tensions between the interests of the central level of the State and local territorial entities, as the latter have to deal with the environmental, social, and cultural consequences of the extraction. This has caused, on one hand, a legal debate on the prevalence of the principles of the Unitary State, and the public and social interest of the mining industry; on the other, the territorial autonomy, and the public and social interest of the environment. This reflection article clarifies the role that territorial entities play in the adoption of decisions related to the mining activity, based on the analysis of the regulatory, legal, constitutional, and case law developments on the subject matter. This shows evidence that territorial authorities have several legal tools that allow them -and, in some cases, impose on them the duty- to actively and efficiently take part on the adoption of authorizations to carry out mining activities in their jurisdiction, which is in line with the coordination, attendance, and subsidiarity.

Keywords: municipalities; mining; participation; environment; referendum; Colombia

\section{SUMARIO}

INTRODUCCIÓN.- I. LA PROPIEDAD ESTATAL DE LOS MINERALES Y LA UTILIDAD PÚBLICA DE LA INDUSTRIA MINERA.- II. PRINCIPIOS QUE DEBEN ORIENTAR LA aCtividad minera en Colombia.- $A$. La participación ciudadana.- B. El principio de la autonomía territorial.- $C$. La conservación ambiental.- D. La participación de las entidades territoriales en la restricción o exclusión de la industria.- 1. El Decreto 934 de 2013.- 2. La Sentencia C-123-14.3. El Decreto 2691 de 2014. E. La acción de los entes territoriales y sus ciudadanos.- F. Límites que puede interponer el constituyente primario.CONCLUSIÓN.- BiBLIOGRAFÍA. 


\section{INTRODUCCIÓN}

Se estima que para mediados de 2013 había 19.000 solicitudes mineras sin responder ${ }^{1}$, y para 2010 ya se habían otorgado alrededor de 9.500 títulos mineros ${ }^{2}$. De acuerdo con esto, la Contraloría General de la República encontró que para julio de 2012 y solo en cuanto a la explotación de oro, seis departamentos del país tenían la cuarta parte o más de su territorio en proceso de solicitud de concesión: Caldas (51\%), Bolívar (35\%), Vaupés (31\%), Antioquia (30\%), Quindío (25\%) y Risaralda (24\%). Para este mismo mineral, ya han sido tituladas grandes extensiones del territorio colombiano en departamentos como Quindío (25\%), Bolívar (13\%), Tolima $(13 \%)$, Antioquia (10\%) y Caldas $(13 \%)^{3}$.

Estas cifras no pueden dar una idea de la preponderancia que ha tomado la participación de las entidades territoriales en las decisiones relacionadas con la exclusión de la totalidad o de parte de su territorio para el desarrollo de actividades mineras y los conflictos que esto genera con las autoridades de orden nacional. Además de los aspectos políticos y sociales relacionados, desde el punto de vista jurídico, también se presenta una tensión entre diferentes principios constitucionales que argumentan la posición del Estado unitario, dueño de los recursos naturales, y la de los entes territoriales con autonomía para decidir sobre las mejores condiciones de desarrollo ambiental, social y cultural en su región, lo que se sustenta de manera general en los principios de organización unitaria del Estado y el de la autonomía de las entidades territoriales, los cuales no

1 Rodrigo E. Negrete-Montes, Derechos, minería y conflictos. Aspectos normativos, en Minería en Colombia: derechos, politicas públicas y gobernanza, 23-56, 24 (LuIs Jorge GARAY-SALAMANCA, dir., Contraloría General de la República, Bogotá, 2013). Disponible en: http://www. contraloria.gov.co/documents/10136/182119332/Libro_mineria_sep3_2013.pdf/65bf77a0-8b0b430a-9726-dad0e72639c6

2 Luis Állvaro Pardo-Becerra, Propuestas para recuperar la gobernanza del sector minero colombiano, en Minería en Colombia: Derechos, politicas públicas y gobernanza, 177-211, 196 (LUIS Jorge Garay-Salamanca, dir., Contraloría General de la República, Bogotá, 2013). Disponible en: http://www.contraloria.gov.co/documents/10136/182119332/Libro_mineria_sep3_2013. pdf/65bf77a0-8b0b-430a-9726-dad0e72639c6

3 Mauricio Cabrera-Leal \& Julio Fierro-Morales, Implicaciones ambientales y sociales del modelo extractivista en Colombia, en Minería en Colombia: Derechos, politicas públicas y gobernanza, 89-124, 97-98 (Luis Jorge GARAY-SAlamanca, dir., Contraloría General de la República, Bogotá, 2013). Disponible en: http://www.contraloria.gov.co/documents/10136/182119332/ Libro_mineria_sep3_2013.pdf/65bf77a0-8b0b-430a-9726-dad0e72639c6 
pueden considerarse como excluyentes, sino como principios que deben desarrollarse de manera complementaria y articulada.

Con el ánimo de dirimir, al menos desde lo jurídico, el conflicto de estos principios, la Corte Constitucional profirió la sentencia C-123-14, en respuesta a la demanda de inconstitucionalidad presentada en contra del artículo 37 del Código de Minas $(\mathrm{CM})^{4}$, el cual prohíbe a las entidades territoriales establecer zonas de exclusión o restricción a la actividad minera dentro de su jurisdicción.

Según el accionante, esta disposición legal vulnera el principio de autonomía de las entidades territoriales, el derecho a un medio ambiente sano y el deber de contribuir a su realización ${ }^{5}$, por lo que solicita al Alto Tribunal declarar la inconstitucionalidad de la norma.

La providencia emitida por la Corte Constitucional en esta ocasión definió las condiciones y el contexto en el que debe interpretarse ese artículo del Código de Minas para ajustarse al ordenamiento constitucional, lo que constituye un tema esencial para la regulación de la actividad minera y del papel de los municipios, departamentos y distritos, en la adopción de autorizaciones para llevar a cabo la minería en sus territorios.

Por otro lado, se ha intentado por diferentes medios prohibir la injerencia de las entidades territoriales en la restricción o exclusión de las actividades mineras en sus territorios, por lo que se han expedido normas reglamentarias como el Decreto 934 de 2013 y el Decreto 2691 de 2014, que fueron suspendidos de manera provisional por el Consejo de Estado. Varios concejos del país, mediante acuerdos municipales, han restringido o excluido la actividad en sus territorios, lo cual también ha motivado diferentes pronunciamientos judiciales en contra. A esto se le suman las consultas populares que han sido convocadas por los alcaldes municipales y por medio de las cuales el pueblo ha decidido excluir la actividad minera de sus regiones.

4 Ley 685 de 2001, por la cual se expide el Código de Minas [CM] y se dictan otras disposiciones, 15 de agosto de 2001, 44.545 Diario Oficial, 8 de septiembre de 2001, art. 37. Disponible en: http://www.secretariasenado.gov.co/senado/basedoc/ley_0685_2001.html

5 Corte Constitucional, Sentencia C-123-14, 5 de marzo de 2014, magistrado ponente Alberto Rojas-Ríos, demanda de inconstitucionalidad contra el artículo 37 de la Ley 685 de 2001 y del artículo 2 (parcial) del Decreto 0934 de 2013, expediente D-9700. Disponible en: http:// www.corteconstitucional.gov.co/relatoria/2014/c-123-14.htm 
Hoy sigue vigente la discusión en torno a la tensión que genera el tema de las industrias extractivas frente a varios principios de orden constitucional, como la autonomía territorial, la participación ciudadana y la conservación ambiental.

A partir de lo anterior, este artículo busca promover una reflexión acerca de los diferentes pronunciamientos y normas que se han expedido sobre el tema, para aclarar el panorama en el que se desenvuelve este debate jurídico para la Nación.

Para llevar a cabo este cometido, en primer lugar, se exponen los principales postulados y principios que están en tensión en torno a la actividad minera, como la propiedad de los recursos minerales en Colombia, la declaración de utilidad pública e interés social de la industria minera, la autonomía territorial, la participación ciudadana y la conservación ambiental. En segundo lugar, se hará un recuento de las normas y providencias judiciales que se han expedido con el objeto de aclarar en qué medida los entes territoriales y los ciudadanos pueden intervenir en la exclusión y restricción de la industria minera en sus territorios.

\section{LA PROPIEDAD ESTATAL DE LOS MINERALES Y LA UTILIDAD PÚBLICA DE LA INDUSTRIA MINERA}

Tal como lo dispone el artículo 332 de la Constitución Política de Colombia (CPC) y el artículo 5 de la Ley 685 de 2001 (CM), el Estado es propietario del subsuelo y de los recursos minerales. De esta forma, por intermedio de la Agencia Nacional de Minería y de algunas gobernaciones delegadas, el Estado autoriza a particulares la explotación de los minerales presentes en el subsuelo al otorgarles concesiones mineras 6 .

La Corte Constitucional se ha pronunciado al respecto al mencionar que la propiedad inmueble se divide en propiedad superficiaria y del subsuelo; al Estado le corresponden la propiedad de este último y de los recursos naturales no renovables que yacen en él o en la superficie, por lo que hay una reserva expresa sobre estos

6 Ley 685 de 2001, por la cual se expide el Código de Minas [CM] y se dictan otras disposiciones, 15 de agosto de 2001, 44.545 Diario Oficial, 8 de septiembre de 2001, art. 14. Disponible en: http://www.secretariasenado.gov.co/senado/basedoc/ley_0685_2001.html 
recursos en cabeza del Estado que involucra la potestad de regular su explotación?.

De acuerdo con el artículo 13 del Código de Minas $^{8}$ y en desarrollo del artículo 58 de la Constitución ${ }^{9}$, se declara de utilidad pública e interés social la industria minera en todas sus ramas y fases. En este sentido, la Corte Constitucional ha establecido que los conceptos de utilidad pública e interés social son determinantes para intervenir en la propiedad y en los derechos económicos individuales y plantea como causa expropiandi o de imposición de servidumbres pues aplica el principio de prevalencia del interés social o público ante el cual debe ceder el interés particular ${ }^{10}$.

Esta declaratoria de utilidad pública e interés social de la actividad minera, no solo puede afectar los derechos económicos individuales de los propietarios del suelo, sino que la privilegia sobre otras actividades que no tienen tal carácter, lo que implica un evidente cambio de uso del suelo, con las consecuentes afectaciones económicas, ambientales, sociales y culturales que pueden traer para el desarrollo de un ente territorial (municipio, distrito o departamento).

Por lo anterior, se hace necesario que la propiedad, administración y potestad regulatoria sobre los minerales que tiene el Estado y la consideración de utilidad pública e interés social de la actividad minera, se ajuste a otros principios y postulados de rango constitucional, como el deber estatal de mejorar la calidad de vida de las personas, garantizar el acceso equitativo a los beneficios del desarrollo y preservar el medio ambiente ${ }^{11}$.

7 Corte Constitucional, Sentencia C-891-02, 22 de octubre de 2002, Expediente 4022, magistrado ponente Jaime Araújo-Rentería. Disponible en: http://www.corteconstitucional.gov. co/relatoria/2002/c-891-02.htm

8 Ley 685 de 2001, por la cual se expide el Código de Minas [CM] y se dictan otras disposiciones, 15 de agosto de 2001, 44.545 Diario Oficial, 8 de septiembre de 2001, art. 13. Disponible en: http://www.secretariasenado.gov.co/senado/basedoc/ley_0685_2001.html

9 Constitución Política [Const], 7 de julio de 1991, art. 58. Versión corregida, 116 Gaceta Constitucional, 20 de julio de 1991, disponible en: http://www.secretariasenado.gov.co/senado/ basedoc/constitucion_politica_1991.html

10 Corte Constitucional, Sentencia C-297-11, 27 de abril de 2011, magistrado ponente Juan Carlos Henao-Pérez. Disponible en: http://www.corteconstitucional.gov.co/relatoria/2011/c-297-11. htm

11 Constitución Política [Const], 7 de julio de 1991, art. 334. Versión corregida, 116 Gaceta Constitucional, 20 de julio de 1991, disponible en: http://www.secretariasenado.gov.co/senado/ basedoc/constitucion_politica_1991.html 


\section{PRINCIPIOS QUE DEBEN ORIENTAR LA ACTIVIDAD MINERA EN COLOMBIA}

La declaratoria de utilidad pública e interés social de una industria como la minería, que trae consigo grandes impactos ambientales, sociales, económicos y culturales, no puede ser un reconocimiento que no admita la modulación con los demás contenidos de la CPC, incluyendo principios rectores de nuestro Estado social de Derecho, como el de la participación ciudadana, la autonomía territorial, la prevalencia de los derechos fundamentales y el deber de conservación del patrimonio natural y cultural de nación, entre otros.

\section{A. La participación ciudadana}

En la CPC, desde el preámbulo, se hace evidente cómo la participación ciudadana constituye una manifestación del principio democrático del Estado Social de Derecho. El artículo 2 de la CPC enumera, entre los fines esenciales del Estado, el de facilitar la participación de todos los miembros de la comunidad colombiana en los asuntos que le competen (económicos, políticos, administrativos y culturales).

La participación ciudadana se puede definir como la facultad que tienen los ciudadanos de escuchar y conocer las propuestas de las entidades estatales y privadas que puedan afectarlos de alguna forma, e intervenir, informarse y comunicar sus intereses frente a ellas $^{12}$, por lo que tiene el carácter de derecho, deber, principio orientador de las actuaciones públicas y fin esencial del Estado,

De manera que, a partir de la participación ciudadana, se abre la posibilidad de tomar parte en la vida social, como miembros de una colectividad y como sujetos de derechos y deberes que deben ejercerse de manera eficaz, mediante las herramientas otorgadas constitucional y legalmente, lo que permite, entre otras cosas, evitar y controlar el abuso del poder político y económico ${ }^{13}$.

12 Corte Constitucional, Sentencia T-348-12, 15 de mayo de 2012, magistrado ponente Jorge Ignacio Pretelt-Chaljub. Disponible en: http://www.corteconstitucional.gov.co/ relatoria/2012/T-348-12.htm

13 Gloria Amparo Rodríguez \& Lina Marcela Muñoz, La participación en la gestión ambiental: un reto para el nuevo milenio, 192 (Universidad del Rosario, Bogotá, 2009). Disponible en: http://philpapers.org/archive/RODLPE.pdf 
De acuerdo con lo anterior, en el ordenamiento jurídico colombiano se han establecido diferentes mecanismos de participación ciudadana que las autoridades deben garantizar y respetar, entre los que podemos enumerar:

- Mecanismos administrativos: la consulta previa ${ }^{14}$, la audiencia ambiental ${ }^{15}$, el derecho de petición ${ }^{16}$ y los recursos en vía gubernativa.

- Mecanismos judiciales: las acciones constitucionales (tutela, popular, de inconstitucionalidad y de cumplimiento) ${ }^{17}$, las acciones contenciosas administrativas (nulidad, restablecimiento del derecho, contractuales) ${ }^{18}$.

14 Constitución Política [Const], 7 de julio de 1991, art. 330. Versión corregida, 116 Gaceta Constitucional, 20 de julio de 1991, disponible en: http://www.secretariasenado.gov.co/senado/ basedoc/constitucion_politica_1991.html. Ley 21 de 1991, por medio de la cual se aprueba el Convenio 169 sobre pueblos indígenas y tribales en países independientes, adoptado por la 76 reunión de la Conferencia General de la Organización Internacional del Trabajo, OIT, Ginebra 1989, 39.720 Diario Oficial, 6 de marzo de 1991. Disponible en: http://www.alcaldiabogota. gov.co/sisjur/normas/Norma1.jsp?i=37032

15 Ley 99 de 1993, por la cual se crea el Ministerio del Medio Ambiente, se reordena el Sector Público encargado de la gestión y conservación del medio ambiente y los recursos naturales renovables, se organiza el Sistema Nacional Ambiental, SINA y se dictan otras disposiciones, 41.146 Diario Oficial, 22 de diciembre de 1993, artículo 72. Disponible en: http://www. secretariasenado.gov.co/senado/basedoc/ley_0099_1993.html. Decreto 330 de 2007, por el cual se reglamentan las audiencias públicas ambientales y se deroga el Decreto 2762 de 2005, 46.536 Diario Oficial, 8 de febrero de 2007. Disponible en: http://www.alcaldiabogota.gov.co/ sisjur/normas/Norma1.jsp?i=22974

16 Constitución Política [Const], 7 de julio de 1991, art. 23. Versión corregida, 116 Gaceta Constitucional, 20 de julio de 1991, disponible en: http://www.secretariasenado.gov.co/senado/basedoc/ constitucion_politica_1991.html. Ley 99 de 1993, por la cual se crea el Ministerio del Medio Ambiente, se reordena el Sector Público encargado de la gestión y conservación del medio ambiente y los recursos naturales renovables, se organiza el Sistema Nacional Ambiental, SINA y se dictan otras disposiciones, 41.146 Diario Oficial, 22 de diciembre de 1993, artículo 74. Disponible en: http://www.secretariasenado.gov.co/senado/basedoc/ley_0099_1993.html

17 Constitución Política [Const], 7 de julio de 1991, arts. 86, 87, 88. Versión corregida, 116 Gaceta Constitucional, 20 de julio de 1991, disponible en: http://www.secretariasenado.gov.co/senado/ basedoc/constitucion_politica_1991.html. Ley 472 de 1998,por la cual se desarrolla el artículo 88 de la Constitución Política de Colombia en relación con el ejercicio de las acciones populares y de grupo y se dictan otras disposiciones, 43.357 Diario Oficial, 6 de agosto de 1998. Disponible en: http://www.secretariasenado.gov.co/senado/basedoc/ley_0472_1998.html

18 Ley 1437 de 2011, por la cual se expide el Código de Procedimiento Administrativo y de lo Contencioso Administrativo, 47.956 Diario Oficial, 18 de enero de 2011, artículos 137, 138 y 141. Disponible en: http://www.secretariasenado.gov.co/senado/basedoc/ley_1437_2011.html 
- Mecanismos políticos: la consulta popular ${ }^{19}$, el cabildo abierto ${ }^{20}$ y la revocatoria del mandato ${ }^{21}$.

\section{B. El principio de la autonomía territorial}

Igualmente, vale la pena resaltar el principio de autonomía territorial, consagrado en los artículos 287 y 288 de la CPC, que disponen que las entidades territoriales poseen un alto nivel de autonomía, en la medida en que tienen el derecho a gobernarse por autoridades propias, ejercer las competencias que les corresponden, administrar los recursos para cumplir sus funciones, participar en las rentas nacionales y gestionar sus intereses locales ${ }^{22}$. Además, es claro que "Las competencias atribuidas a los distintos niveles territoriales serán ejercidas conforme a los principios de coordinación, concurrencia y subsidiariedad en los términos que establezca la ley" ${ }^{23}$.

Por otro lado, el artículo 311 de la Carta Política asigna a los municipios la función de "...ordenar el desarrollo de su territorio, promover la participación comunitaria, el mejoramiento social y cultural de sus habitantes y cumplir las demás funciones que le asignen la Constitución y las leyes" ${ }^{24}$. El artículo 313 otorga a los Concejos Municipales la función de reglamentar los usos del suelo dentro de los límites legales ${ }^{25}$. Por esto, tal como lo ha manifestado la Corte Constitucional, gran parte de la esencia del principio de

19 Ley 134 de 1994, por la cual se dictan normas sobre mecanismos de participación ciudadana, 41.373 Diario Oficial, 31 de mayo de 1994, artículo 50 ss. Disponible en: http://www. secretariasenado.gov.co/senado/basedoc/ley_0134_1994.html

20 Ley 134 de 1994, por la cual se dictan normas sobre mecanismos de participación ciudadana, 41.373 Diario Oficial, 31 de mayo de 1994, artículo 81 ss. Disponible en: http://www. secretariasenado.gov.co/senado/basedoc/ley_0134_1994.html

21 Ley 134 de 1994, por la cual se dictan normas sobre mecanismos de participación ciudadana, 41.373 Diario Oficial, 31 de mayo de 1994, artículo 64 ss. Disponible en: http://www. secretariasenado.gov.co/senado/basedoc/ley_0134_1994.html

22 Constitución Política [Const], 7 de julio de 1991, art. 287. Versión corregida, 116 Gaceta Constitucional, 20 de julio de 1991, disponible en: http://www.secretariasenado.gov.co/senado/ basedoc/constitucion_politica_1991.html

23 Constitución Política [Const], 7 de julio de 1991, art. 288. Versión corregida, 116 Gaceta Constitucional, 20 de julio de 1991, disponible en: http://www.secretariasenado.gov.co/senado/ basedoc/constitucion_politica_1991.html

24 Constitución Política [Const], 7 de julio de 1991, art. 311. Versión corregida, 116 Gaceta Constitucional, 20 de julio de 1991, disponible en: http://www.secretariasenado.gov.co/senado/ basedoc/constitucion_politica_1991.html

25 Constitución Política [Const], 7 de julio de 1991, art. 313. Versión corregida, 116 Gaceta Constitucional, 20 de julio de 1991, disponible en: http://www.secretariasenado.gov.co/senado/ basedoc/constitucion_politica_1991.html 
autonomía territorial “...se manifiesta en la posibilidad de que los municipios reglamenten los usos del suelo dentro de su respectivo territorio" 26 .

\section{La conservación ambiental}

Entre los principios fundamentales establecidos en la CPC de 1991, se reconoce a Colombia como un estado social de derecho participativo y pluralista, fundado en el respeto por la dignidad humana, que entre sus fines esenciales tiene la obligación de garantizar la efectividad de los derechos y deberes constitucionales y la protección de todas las personas residentes en Colombia en su vida, honra, bienes y creencias ${ }^{27}$. Lo anterior tiene estrecha relación con el ambiente, teniendo en cuenta que como entorno vital del ser humano, de su conservación depende la supervivencia de las generaciones presentes y futuras.

Por tanto, el tema ambiental tiene gran relevancia en el ordenamiento constitucional colombiano, tanto que se ha reconocido su concepción ecologista a partir de disposiciones como las contempladas en los artículos 2, 8, 29, 58, 67, 79, 80 y 95, según las cuales el ambiente sano es un derecho en cabeza de todas las personas, que deben participar en su conservación ${ }^{28}$. Además, se reconocen como deberes estatales, la protección de la diversidad e integridad del ambiente, la salvaguarda de las riquezas naturales de la Nación, la conservación de las áreas de especial importancia ecológica, la garantía de la conservación y restauración de los recursos naturales, la prevención y control de los factores de deterioro ambiental, entre otros ${ }^{29}$.

26 Corte Constitucional, Sentencia C-123-14, 5 de marzo de 2014, magistrado ponente Alberto Rojas-Ríos, demanda de inconstitucionalidad contra el artículo 37 de la Ley 685 de 2001 y del artículo 2 (parcial) del Decreto 0934 de 2013, expediente D-9700. Disponible en: http:// www.corteconstitucional.gov.co/relatoria/2014/c-123-14.htm

27 Constitución Política [Const], 7 de julio de 1991, arts. 1 y 2. Versión corregida, 116 Gaceta Constitucional, 20 de julio de 1991, disponible en: http://www.secretariasenado.gov.co/senado/ basedoc/constitucion_politica_1991.html

28 Corte Constitucional, Sentencia T-760-07, 25 de septiembre de 2007, magistrado ponente Clara Inés Vargas-Hernández. Disponible en: http://www.corteconstitucional.gov.co/ relatoria/2007/t-760-07.htm

29 Corte Constitucional, Sentencia C-431-00, 12 de abril de 2000, magistrado ponente Vladimiro Naranjo-Mesa. Disponible en: http://www.corteconstitucional.gov.co/relatoria/2000/c-431-00. htm 
En este orden de ideas, la protección del ambiente desde su dimensión de derecho humano, deber general y fin estatal, al relacionarse a su vez con otros derechos como el de la vida y la salud, encuentra su sustento en el bien común y la prevalencia del interés general $^{30}$

\section{La participación de las entidades territoriales en la restricción o exclusión de la industria minera en sus territorios}

De acuerdo con las alarmantes cifras de áreas destinadas para la actividad minera, la Contraloría General de la República ha estimado que esta actividad podría llegar a ocupar la tercera parte del territorio nacional ${ }^{31}$, por lo que es evidente el gran impacto social, económico, cultural y ambiental que las concesiones mineras pueden tener sobre el uso del suelo y el ordenamiento territorial de los diferentes municipios y departamentos del país.

Lo anterior nos lleva a reflexionar sobre las diferentes posibilidades que tienen las administraciones locales y los ciudadanos para participar en las decisiones relacionadas con el desarrollo de la actividad minera en sus territorios.

De acuerdo con los artículos 333 y 334 de la CPC, por mandato de la ley, el Estado delimitará e intervendrá para racionalizar la economía, en la libertad económica y la explotación, entre otros, de los recursos minerales, cuando así lo exijan el interés social, el ambiente y el patrimonio cultural de la Nación, para conseguir el mejoramiento de la calidad de vida de los habitantes, la distribución equitativa de las oportunidades y los beneficios del desarrollo y la preservación de un ambiente sano.

Según lo dispuesto en el artículo 37 del Código de Minas, el establecimiento de zonas restringidas o excluidas dentro del terri-

30 Rafael E. Wilches-Durán, Principio ambiental de precaución y contratación mercantil en derecho colombiano. Planteamiento del problema, 123 Vniversitas, 283-314 (2011). Disponible en: http://vniversitasjuridica.javeriana.edu.co/descargas.php?archivo=Universitas-123\%20 $-\%$ 209.pdf\&idArt $=313 \&$ edicion $=123$

31 Rodrigo E. Negrete-Montes, Derechos, minería y conflictos. Aspectos normativos, en Minería en Colombia: Derechos, politicas públicas y gobernanza, 23-56, 24 (LuIs Jorge Garay-SAlaMANCA, dir., Contraloría General de la República, Bogotá, 2013). Disponible en: http://www. contraloria.gov.co/documents/10136/182119332/Libro_mineria_sep3_2013.pdf/65bf77a0-8b0b430a-9726-dad0e72639c6 
torio nacional solo corresponde a la autoridad ambiental y minera, es decir, el Ministerio de Ambiente y Desarrollo Sostenible, las corporaciones autónomas regionales, las de desarrollo sostenible y los distritos especiales y la Agencia Nacional de Minería, ANM, o quien haga sus veces ${ }^{32}$.

Respecto a las zonas de exclusión, el Código de Minas ${ }^{33}$ establece que no podrán ejecutarse trabajos y obras de exploración y explotación mineras en:

1. Áreas que integran el sistema de parques nacionales naturales

2. Parques naturales de carácter regional

3. Zonas de reserva forestal

Igualmente, por vía jurisprudencial, la Corte Constitucional estableció que puede haber otras zonas excluibles de la minería declaradas con anterioridad o que se declaren en el futuro por parte de la autoridad ambiental, aun cuando esas zonas no se enmarquen en las categorías de protección enunciadas en el artículo $34^{34}$, como los ecosistemas de páramo y los humedales designados en la lista de importancia internacional de la Convención Ramsar ${ }^{35}$.

\section{El Decreto 934 de 2013}

El 9 de mayo de 2013, la Presidencia de la República expidió el Decreto $934^{36}$ con el objeto de reglamentar el mencionado artículo 37 del Código de Minas. Este Decreto estableció que, teniendo en cuenta el carácter de utilidad pública e interés social de la minería,

32 Constitución Política [Const], 7 de julio de 1991, art. 37. Versión corregida, 116 Gaceta Constitucional, 20 de julio de 1991, disponible en: http://www.secretariasenado.gov.co/senado/ basedoc/constitucion_politica_1991.html

33 Ley 685 de 2001, por la cual se expide el Código de Minas [CM] y se dictan otras disposiciones, 15 de agosto de 2001, 44.545 Diario Oficial, 8 de septiembre de 2001, art. 34. Disponible en: http://www.secretariasenado.gov.co/senado/basedoc/ley_0685_2001.html

34 Corte Constitucional, Sentencia C-339-02, 7 de mayo de 2002, Expediente D-3767, magistrado ponente Jaime Araújo-Rentería. Disponible en: http://www.corteconstitucional.gov.co/ relatoria/2002/c-339-02.htm.

35 Convención Relativa a los Humedales de Importancia Internacional especialmente como Hábitat de Aves Acuáticas o Convenio de Ramsar, Ramsar (Irán), 18 de enero de 1971, en vigor: 21 de diciembre de 1975. Disponible en: http://www.ramsar.org/es

36 Decreto 934 de 2013, por el cual se reglamentan el artículo 37 de la Ley 685 de 2001, 48.785 Diario Oficial, 9 de mayo de 2013, artículo 2. Disponible en: http://www.alcaldiabogota.gov. co/sisjur/normas/Norma1.jsp?i=53052 
las autoridades ambientales y mineras son las únicas competentes para excluir o restringir las actividades relacionadas con esta industria, por lo que las entidades territoriales no están facultadas para tomar decisiones relacionadas con el ordenamiento de esta actividad dentro de su territorio, a partir de los instrumentos de ordenamiento territorial, como los planes de ordenamiento territorial, planes básicos de ordenamiento territorial o esquemas de ordenamiento territorial de los municipios y distritos (artículos 1 y 2, Decreto 934 de 2013) ${ }^{37}$.

Entonces, según lo dispuesto en esta norma, los concejos municipales y las asambleas departamentales carecen de competencia para establecer zonas dentro de su jurisdicción que puedan ser excluidas de la actividad minera o imponer limitaciones con respecto a esta actividad, lo que corresponde exclusivamente a las autoridades del orden nacional.

Con ocasión de una demanda presentada por la Contraloría General de la República ante el Consejo de Estado, en ejercicio del medio de control de nulidad, el 3 de septiembre de 2014, la Sección Tercera del máximo tribunal de lo contencioso administrativo ordenó la suspensión provisional del Decreto 934 de $2013^{38}$.

La parte actora argumentó que la norma demandada va en contravía de la CPC, pues vulnera la autonomía de los entes territoriales, al prohibirles reglamentar y ordenar el uso de suelo en sus jurisdicciones con respecto a las actividades mineras, así como un desconocimiento del deber de planificación y conservación de los

37 Decreto 934 de 2013, por el cual se reglamentan el artículo 37 de la Ley 685 de 2001, 48.785 Diario Oficial, 9 de mayo de 2013. Disponible en: http://www.alcaldiabogota.gov.co/sisjur/ normas/Norma1.jsp?i=53052. Artículo 1. La decisión de establecer zonas excluidas y restringidas de minería compete exclusivamente, y dentro de los límites fijados en los artículos 34 y 35 de la Ley 685 de 2001, a las autoridades minera y ambiental, quienes actuarán con base en estudios técnicos, económicos, sociales y ambientales y dando aplicación al principio del desarrollo sostenible.

Artículo 2. Dado el carácter de utilidad pública e interés social de la minería, a través del Ordenamiento Territorial no es posible hacer directa ni indirectamente el Ordenamiento Minero, razón por la cual los planes de ordenamiento territorial, planes básicos de ordenamiento territorial o esquemas de ordenamiento territorial de los municipios y distritos no podrán incluir disposiciones que impliquen un ordenamiento de la actividad minera en el ámbito de su jurisdicción, salvo previa aprobación de las autoridades nacionales.

38 Consejo de Estado, Sala de lo Contencioso Administrativo, Sección Tercera, Proceso 1100103260020130016200,3 de septiembre de 2014, consejero ponente Hernán Andrade-Rincón. Disponible en: http://190.24.134.67/documentos/sentencias/11001032600020130016200.pdf 
recursos naturales, el derecho a un ambiente sano y la participación ciudadana en temas ambientales.

El Despacho consideró que el Decreto reglamentario en estudio descarta totalmente la facultad que tienen los entes territoriales para reglamentar y definir los usos del suelo en el territorio de su jurisdicción, en lo que respecta a la industria minera, lo que va en contravía del derecho que tienen estas entidades de gobernarse por autoridades propias ${ }^{39}$ y su competencia de reglamentación de usos del suelo ${ }^{40}$. Además de desconocer la esencia propia de los instrumentos de ordenamiento territorial entendidos "como el conjunto de directrices, políticas, estrategias, metas, programas, actuaciones y normas que debe adoptar cada municipio para orientar y administrar el desarrollo físico del territorio y la utilización del suelo" ${ }^{\prime 1}$, lo que representa una vulneración al principio de autonomía territorial.

Así mismo, el Consejo de Estado determinó que el Decreto 934 de 2013 desconoce de manera directa una facultad expresa que otorga el Código de Minas a los entes territoriales, específicamente en lo relacionado con el contenido del artículo 35, literal a), teniendo en cuenta que prohíbe de manera absoluta cualquier restricción a la actividad minera por parte de las entidades territoriales, mientras que el Código de Minas vigente, las faculta para restringir el desarrollo de esta industria, dentro de su perímetro urbano, mediante Acuerdos Municipales ${ }^{42}$.

Así las cosas, la Sección Tercera del Consejo de Estado resolvió suspender de manera provisional el Decreto 934 de 2013, en el entendido de que desconoce el principio de autonomía de las entidades territoriales.

39 Constitución Política [Const], 7 de julio de 1991, art. 287. Versión corregida, 116 Gaceta Constitucional, 20 de julio de 1991, disponible en: http://www.secretariasenado.gov.co/senado/ basedoc/constitucion_politica_1991.html

40 Constitución Política [Const], 7 de julio de 1991, arts. 311 y 313, numeral 7. Versión corregida, 116 Gaceta Constitucional, 20 de julio de 1991, disponible en: http://www.secretariasenado. gov.co/senado/basedoc/constitucion_politica_1991.html

41 Consejo de Estado, Sala de lo Contencioso Administrativo, Sección Tercera, Proceso 7300123-31-000-2002-00575-01, 29 de enero de 2004, consejero ponente Ramiro Saavedra-Becerra. Disponible en: http://juriscundi.cundinamarca.gov.co/public/document/view/id/3072

42 Ley 685 de 2001, por la cual se expide el Código de Minas [CM] y se dictan otras disposiciones, 15 de agosto de 2001, 44.545 Diario Oficial, 8 de septiembre de 2001, art. 35, literal a. Disponible en: http://www.secretariasenado.gov.co/senado/basedoc/ley_0685_2001.html 


\section{La Sentencia C-123-14}

El 5 de marzo de 2014, mediante la Sentencia C-123-14, la Sala Plena de la Corte Constitucional resolvió la demanda de inconstitucionalidad contra el artículo 37 del CM, el cual dispone:

Artículo 37. Prohibición legal. Con excepción de las facultades de las autoridades nacionales y regionales que se señalan en los artículos 34 y 35 anteriores, ninguna autoridad regional, seccional o local podrá establecer zonas del territorio que queden permanente o transitoriamente excluidas de la minería.

Esta prohibición comprende los planes de ordenamiento territorial de que trata el siguiente artículo.

Esta acción fue presentada bajo el argumento de que la norma demandada desconoce la autonomía de las entidades territoriales para decidir sobre los usos del suelo en lo relativo a excluir la actividad minera de sus territorios.

Esta contradicción también se señaló en la demanda frente al artículo 2 del Decreto 934 de 2013, que dispone que mediante los instrumentos de ordenamiento territorial, no es posible ordenar la actividad minera en el territorio de jurisdicción de las entidades territoriales.

Entonces, según el demandante, lo dispuesto en el artículo 37 y el artículo 2 del Decreto 934 de 2013 va en contravía de las disposiciones constitucionales relacionadas con la autonomía de las entidades territoriales, el derecho a un ambiente sano y el deber de contribuir a su realización. Teniendo en cuenta que, según los artículos 287 y 288 de la CPC, en virtud de la autonomía de la que gozan las entidades territoriales, estas tienen derecho a gobernarse por autoridades propias, administrar los recursos y tributos necesarios para cumplir sus funciones, participar en las rentas nacionales y ejercer sus competencias en el marco de los principios de coordinación, concurrencia y subsidiariedad ${ }^{43}$.

Por lo tanto, el accionante afirmó en su momento que aun cuando en la Carta Política se establezca la propiedad estatal de los recursos

43 Constitución Política [Const], 7 de julio de 1991, arts. 287 y 288. Versión corregida, 116 Gaceta Constitucional, 20 de julio de 1991, disponible en: http://www.secretariasenado.gov.co/senado/ basedoc/constitucion_politica_1991.html 
no renovables ${ }^{44}$, la intervención estatal en su explotación y el uso del suelo ${ }^{45}$, y se consagra que es la ley la que debe determinar las condiciones en que se llevará a cabo la explotación de los recursos naturales, no puede desconocerse el principio de autonomía de las entidades territoriales y prohibirse su intervención en este tipo de decisiones.

Además se argumentó una violación al principio de descentralización administrativa, según el cual los entes territoriales deben ejercer sus competencias en el marco de los principios de coordinación, concurrencia y subsidiariedad, tal como está dispuesto en el artículo 288 de la Constitución, teniendo en cuenta que los intereses territoriales son articulables y no enfrentados ${ }^{46}$. En esta ocasión, la Corte Constitucional señaló que los principios de concurrencia, coordinación y subsidiariedad se enfocan en la articulación del ejercicio de las competencias correspondientes al sector centralizado y a las entidades territoriales.

El principio de coordinación exige el ejercicio armónico y complementario de las competencias para la consecución de los fines estatales, sin que haya interferencia u obstaculización en el ejercicio de funciones por parte de las autoridades competentes ${ }^{47}$. Por su parte, el principio de concurrencia involucra la participación de los distintos niveles de la administración en la formulación, ejecución y seguimiento de acciones de forma conjunta, enfocadas al mismo objetivo, de manera eficiente y a partir del respeto mutuo hacia las competencias de cada una de las entidades. Finalmente, el principio de subsidiariedad hace referencia al apoyo transitorio

44 Constitución Política [Const], 7 de julio de 1991, art. 332.6. Versión corregida, 116 Gaceta Constitucional, 20 de julio de 1991, disponible en: http://www.secretariasenado.gov.co/senado/ basedoc/constitucion_politica_1991.html

45 Constitución Política [Const], 7 de julio de 1991, art. 6. Versión corregida, 116 Gaceta Constitucional, 20 de julio de 1991, disponible en: http://www.secretariasenado.gov.co/senado/ basedoc/constitucion_politica_1991.html

46 Corte Constitucional, Sentencia C-123-14, 5 de marzo de 2014, magistrado ponente Alberto Rojas-Ríos, demanda de inconstitucionalidad contra el artículo 37 de la Ley 685 de 2001 y del artículo 2 (parcial) del Decreto 0934 de 2013, expediente D-9700. Disponible en: http:// www.corteconstitucional.gov.co/relatoria/2014/c-123-14.htm

47 Ley 489 de 1998, por la cual se dictan normas sobre la organización y funcionamiento de las entidades del orden nacional, se expiden las disposiciones, principios y reglas generales para el ejercicio de las atribuciones previstas en los numerales 15 y 16 del artículo 189 de la Constitución Política y se dictan otras disposiciones, 43.464 Diario Oficial, 30 de diciembre de 1998. Disponible en: http://www.secretariasenado.gov.co/senado/basedoc/ley_0489_1998. html 
de las autoridades de nivel superior a aquellas de nivel inferior en acciones propias de las autoridades de nivel inferior ${ }^{48}$.

Con respecto a la aplicación de estos principios, el Alto Tribunal Constitucional consideró que aun cuando se argumente que la limitación impuesta a los entes territoriales se sustenta en el principio constitucional de organización unitaria de Estado ${ }^{49}$ y la preeminencia de la Nación en la formulación de políticas públicas relacionadas con la explotación de minerales ${ }^{50}$, debe buscarse una armonización con los principios de autonomía territorial y descentralización de las entidades territoriales, teniendo presente que:

...el artículo 37 de la ley 685 de 2001 —Código de Minas — estará acorde con la Constitución, siempre y cuando en el proceso de autorización para la realización de actividades de exploración y explotación minera -cualquiera sea el nombre que se dé al procedimiento para expedir dicha autorización por parte del Estado - se tengan en cuenta los aspectos de coordinación y concurrencia, los cuales se fundan en el principio constitucional de autonomía territorial. En este sentido, una autorización al respecto deberá dar la oportunidad de participar activa y eficazmente a las entidades municipales o distritales involucradas en dicho proceso, mediante acuerdos sobre la protección de cuencas hídricas

48 Procuraduría Delegada para la Descentralización de las Entidades Territoriales. Descentralización y entidades territoriales, 23 (Instituto de Estudios del Ministerio Público, Bogotá, 2011 ). Disponible en: http://www.procuraduria.gov.co/portal/media/file/Cartilla\%20descentralizaci $\% \mathrm{C} 3 \% \mathrm{~B} 3 \mathrm{n} . \mathrm{pdf}$

49 Constitución Política [Const], 7 de julio de 1991, art. 1. Versión corregida, 116 Gaceta Constitucional, 20 de julio de 1991, disponible en: http://www.secretariasenado.gov.co/senado/basedoc/ constitucion_politica_1991.html. "Colombia es un Estado social de derecho, organizado en forma de República unitaria, descentralizada, con autonomía de sus entidades territoriales, democrática, participativa y pluralista, fundada en el respeto de la dignidad humana, en el trabajo y la solidaridad de las personas que la integran y en la prevalencia del interés general".

50 Artículo 332 de la Constitución. El Estado es propietario del subsuelo y de los recursos naturales no renovables, sin perjuicio de los derechos adquiridos y perfeccionados con arreglo a las leyes preexistentes.

Artículo 334. La dirección general de la economía estará a cargo del Estado. Este intervendrá, por mandato de la ley, en la explotación de los recursos naturales, en el uso del suelo, en la producción, distribución, utilización y consumo de los bienes, y en los servicios públicos y privados, para racionalizar la economía con el fin de conseguir en el plano nacional y territorial, en un marco de sostenibilidad fiscal, el mejoramiento de la calidad de vida de los habitantes, la distribución equitativa de las oportunidades y los beneficios del desarrollo y la preservación de un ambiente sano. Dicho marco de sostenibilidad fiscal deberá fungir como instrumento para alcanzar de manera progresiva los objetivos del Estado Social de Derecho. En cualquier caso, el gasto público social será prioritario. 
y la salubridad de la población, así como, del desarrollo económico, social y cultural de sus comunidades ${ }^{51}$.

Entonces, según lo dispuesto en la sentencia de exequibilidad del artículo 37 del Código de Minas, para otorgar cualquier autorización relacionada con la actividad minera, las autoridades del nivel nacional deben garantizar una participación real y efectiva de las autoridades municipales y distritales y, de esta manera, adoptar en conjunto las medidas necesarias para la protección de las cuencas hídricas, el desarrollo económico, social y cultural, la salubridad de la población y la protección ambiental del municipio, bajo los lineamientos de los principios de coordinación, concurrencia y subsidiariedad $^{52}$.

\section{E1 Decreto 2691 de 2014}

En este sentido, con el objeto de regular el procedimiento mediante el cual los municipios y distritos pueden participar en el establecimiento de medidas de protección del ambiente, la salubridad, el desarrollo económico, social y cultural de sus comunidades, frente a la actividad minera, y dar cumplimiento a los dispuesto en la Sentencia C-123-14, la Presidencia de la República expidió el Decreto 2691 de 2014, en el que se dispone que los concejos municipales o distritales pueden solicitar ante el Ministerio de Minas y Energía, dichas medidas de protección, previa expedición de un acuerdo que las soporte y la delimitación de las áreas objeto de estas medidas ${ }^{53}$.

Según el citado Decreto, en este acuerdo, se deberán sustentar las causas y finalidades de estas medidas de protección, así como los

51 Corte Constitucional, Sentencia C-123-14, 5 de marzo de 2014, magistrado ponente Alberto Rojas-Ríos, demanda de inconstitucionalidad contra el artículo 37 de la Ley 685 de 2001 y del artículo 2 (parcial) del Decreto 0934 de 2013, expediente D-9700. Disponible en: http:// www.corteconstitucional.gov.co/relatoria/2014/c-123-14.htm

52 Corte Constitucional, Sentencia C-123-14, 5 de marzo de 2014, magistrado ponente Alberto Rojas-Ríos, demanda de inconstitucionalidad contra el artículo 37 de la Ley 685 de 2001 y del artículo 2 (parcial) del Decreto 0934 de 2013, expediente D-9700. Disponible en: http:// www.corteconstitucional.gov.co/relatoria/2014/c-123-14.htm

53 Decreto 2691 de 2014, por el cual se reglamenta el artículo 37 de la Ley 685 de 2001 y se definen los mecanismos para acordar con las autoridades territoriales las medidas necesarias para la protección del ambiente sano, y en especial, de sus cuencas hídricas, el desarrollo económico, social, cultural de sus comunidades y la salubridad de la población, en desarrollo del proceso de autorización de actividades de exploración y explotación minera, 49.374 Diario Oficial, 23 de diciembre de 2014, artículo 3. Disponible en: http://www.alcaldiabogota.gov.co/sisjur/ normas/Norma1.jsp?i=60227 
estudios técnicos que justifiquen su pertinencia social, económica, cultural o ambiental, frente a los impactos que la actividad minera pueda ocasionar. Los estudios estarán a cargo del ente territorial y deberán estar en consonancia con los respectivos instrumentos de ordenamiento territorial ${ }^{54}$.

Así mismo, el Decreto brinda a las entidades territoriales un término de noventa (90) días, contados a partir de su publicación del mismo, para presentar las solicitudes de protección ante el Ministerio de Minas y Energía ${ }^{55}$, el cual venció el 3 de marzo de 2015 sin que muchos entes territoriales pudieran presentarlas debido a sus deficiencias institucionales y financieras para realizar los estudios requeridos.

La norma estableció un procedimiento según el cual, una vez recibida la solicitud por parte del Ministerio de Minas y Energía, este la remitirá a las autoridades del orden nacional competentes, dentro de los diez (10) días siguientes, para que en un término de veinte (20) días emitan su concepto, el cual podrá soportarse en las consideraciones que aporten las entidades del sector ${ }^{56}$ y contendrá las consideraciones acerca de la procedencia y las condiciones de las medidas de protección solicitadas. Además, el Ministerio de Minas y Energía podrá solicitar el concepto del Departamento Nacional de Planeación, DNP, y a las empresas del gremio minero acerca del impacto económico que puedan ocasionar las medidas de

54 Decreto 2691 de 2014, por el cual se reglamenta el artículo 37 de la Ley 685 de 2001 y se definen los mecanismos para acordar con las autoridades territoriales las medidas necesarias para la protección del ambiente sano, y en especial, de sus cuencas hídricas, el desarrollo económico, social, cultural de sus comunidades y la salubridad de la población, en desarrollo del proceso de autorización de actividades de exploración y explotación minera, 49.374 Diario Oficial, 23 de diciembre de 2014, artículo 4. Disponible en: http://www.alcaldiabogota.gov.co/sisjur/ normas/Normal.jsp?i=60227

55 Decreto 2691 de 2014, por el cual se reglamenta el artículo 37 de la Ley 685 de 2001 y se definen los mecanismos para acordar con las autoridades territoriales las medidas necesarias para la protección del ambiente sano, y en especial, de sus cuencas hídricas, el desarrollo económico, social, cultural de sus comunidades y la salubridad de la población, en desarrollo del proceso de autorización de actividades de exploración y explotación minera, 49.374 Diario Oficial, 23 de diciembre de 2014, artículo 5. Disponible en: http://www.alcaldiabogota.gov.co/sisjur/ normas/Norma1.jsp?i $=60227$

56 Decreto 2691 de 2014, por el cual se reglamenta el artículo 37 de la Ley 685 de 2001 y se definen los mecanismos para acordar con las autoridades territoriales las medidas necesarias para la protección del ambiente sano, y en especial, de sus cuencas hídricas, el desarrollo económico, social, cultural de sus comunidades y la salubridad de la población, en desarrollo del proceso de autorización de actividades de exploración y explotación minera, 49.374 Diario Oficial, 23 de diciembre de 2014, artículo 6. Disponible en: http://www.alcaldiabogota.gov.co/sisjur/ normas/Norma1.jsp?i=60227 
protección y la conveniencia de los proyectos mineros en cuestión, para adoptar una decisión ${ }^{57}$.

Según este Decreto, una vez surtido este trámite, el Ministerio de Minas y Energía citará a una única reunión con el concejo municipal o distrital solicitante y las entidades y organismos que considere pertinentes, con el fin de expresar las razones de las solicitudes y de los conceptos emitidos ${ }^{58}$, y en un plazo de quince (15) días el Ministerio decidirá sobre la adopción o no de las medidas de protección solicitadas, con base en los principios de desarrollo sostenible, fortalecimiento económico y social del país, propiedad estatal de los recursos naturales no renovables y su aprovechamiento eficiente ${ }^{59}$.

Ahora bien, este Decreto 2691 de 2014 hace surgir algunas inquietudes con respecto a lo dispuesto en la Sentencia C-123-14, pues aun cuando pretende regular el procedimiento mediante el cual los municipios y distritos pueden participar en el proceso de autorización para la realización de actividades de exploración y explotación minera en los territorios de su jurisdicción, ¿realmente este procedimiento garantiza una participación activa y eficaz de los entes territoriales?, ¿permite la materialización de los principios de coordinación y concurrencia, la autonomía territorial y la descentralización de las entidades territoriales?, ¿permite la formulación

57 Decreto 2691 de 2014, por el cual se reglamenta el artículo 37 de la Ley 685 de 2001 y se definen los mecanismos para acordar con las autoridades territoriales las medidas necesarias para la protección del ambiente sano, y en especial, de sus cuencas hídricas, el desarrollo económico, social, cultural de sus comunidades y la salubridad de la población, en desarrollo del proceso de autorización de actividades de exploración y explotación minera, 49.374 Diario Oficial, 23 de diciembre de 2014, artículo 7. Disponible en: http://www.alcaldiabogota.gov.co/sisjur/ normas/Norma1.jsp?i=60227

58 Decreto 2691 de 2014, por el cual se reglamenta el artículo 37 de la Ley 685 de 2001 y se definen los mecanismos para acordar con las autoridades territoriales las medidas necesarias para la protección del ambiente sano, y en especial, de sus cuencas hídricas, el desarrollo económico, social, cultural de sus comunidades y la salubridad de la población, en desarrollo del proceso de autorización de actividades de exploración y explotación minera, 49.374 Diario Oficial, 23 de diciembre de 2014, artículo 8. Disponible en: http://www.alcaldiabogota.gov.co/sisjur/ normas/Norma1.jsp?i=60227

59 Decreto 2691 de 2014, por el cual se reglamenta el artículo 37 de la Ley 685 de 2001 y se definen los mecanismos para acordar con las autoridades territoriales las medidas necesarias para la protección del ambiente sano, y en especial, de sus cuencas hídricas, el desarrollo económico, social, cultural de sus comunidades y la salubridad de la población, en desarrollo del proceso de autorización de actividades de exploración y explotación minera, 49.374 Diario Oficial, 23 de diciembre de 2014, artículo 9. Disponible en: http://www.alcaldiabogota.gov.co/sisjur/ normas/Norma1.jsp?i=60227 
de acuerdos para la protección de cuencas hídricas y la salubridad de la población?

En torno a estos interrogantes, el Decreto genera muchas preocupaciones, pues el procedimiento allí establecido representa varios obstáculos para la participación de los municipios y distritos en un tema tan trascendente para la vida local como el desarrollo de proyectos mineros. En primer lugar, establece que los estudios que soporten las solicitudes de protección deben ser costeados por los entes territoriales que las formulen, además de tener que reformar sus instrumentos de ordenamiento territorial ${ }^{60}$, lo que resulta inviable en la mayoría de los casos, debido a la falta de recursos económicos, humanos y técnicos de muchos de los municipios del país.

Por otro lado, la participación que se les otorga a los entes territoriales se limita a la presentación de una solicitud de medidas de protección ante el Ministerio de Minas y Energía, que será el que adopte la decisión definitiva sobre su pertinencia o condicionamiento ${ }^{61}$, determinación que será consultada incluso con las empresas del sector minero, sin ninguna posibilidad real de concertación con los entes territoriales involucrados. Entonces, las posibilidades de adopción de las medidas de protección solicitadas son muy bajas, si se tiene en cuenta que la decisión en manos del Ministerio de Minas y Energía se adoptará teniendo en cuenta criterios económicos y de desarrollo justificados por las empresas y entidades del sector minero. Todo lo anterior aparta el Decreto 2691 de 2014 de lo dispuesto por la Corte Constitucional en la Sentencia C-123-14. Por lo anterior, el 25 de junio de 2015, la Sección Primera de la Sala de lo Contencioso Administrativo ${ }^{62}$ decretó la suspensión

60 Decreto 2691 de 2014, por el cual se reglamenta el artículo 37 de la Ley 685 de 2001 y se definen los mecanismos para acordar con las autoridades territoriales las medidas necesarias para la protección del ambiente sano, y en especial, de sus cuencas hídricas, el desarrollo económico, social, cultural de sus comunidades y la salubridad de la población, en desarrollo del proceso de autorización de actividades de exploración y explotación minera, 49.374 Diario Oficial, 23 de diciembre de 2014, artículo 4. Disponible en: http://www.alcaldiabogota.gov.co/sisjur/ normas/Norma1.jsp?i=60227

61 Decreto 2691 de 2014, por el cual se reglamenta el artículo 37 de la Ley 685 de 2001 y se definen los mecanismos para acordar con las autoridades territoriales las medidas necesarias para la protección del ambiente sano, y en especial, de sus cuencas hídricas, el desarrollo económico, social, cultural de sus comunidades y la salubridad de la población, en desarrollo del proceso de autorización de actividades de exploración y explotación minera, 49.374 Diario Oficial, 23 de diciembre de 2014, artículo 9. Disponible en: http://www.alcaldiabogota.gov.co/sisjur/ normas/Norma1.jsp?i=60227

62 Consejo de Estado, Sala de lo Contencioso Administrativo, Sección Primera, Proceso 
provisional del Decreto 2691 de 2014, en el marco de la Acción de Nulidad presentada por el Grupo de Acciones Públicas de la Universidad del Rosario, GAP.

En esta oportunidad, la parte actora presentó cargos relacionados con la falta de competencia del Presidente de la República para crear procedimientos administrativos y la vulneración al principio de la autonomía territorial, teniendo en cuenta que el Decreto 2691 de 2014 establece un procedimiento estricto, exigente y costoso, que impide que las entidades territoriales ejerzan un control y una participación real y efectiva frente a la autorización de llevar a cabo proyectos mineros en el territorio.

El máximo Tribunal de lo Contencioso Administrativo acogió la solicitud de suspensión provisional del Decreto, al considerar que, por un lado, las autoridades administrativas dentro de su potestad reglamentaria, carecen de competencia para crear nuevos procedimientos administrativos, ya que de conformidad con lo dispuesto en los artículos 29, 114 y 150 de la CPC, el único que posee esta facultad es el Legislador.

Por otro lado, el Consejo de Estado determinó que, aunque el Decreto pretende dar cumplimiento a lo ordenado en la Sentencia C-123-14, va en clara contravía con lo dispuesto en esta decisión de la Corte Constitucional, en la que se estableció que el artículo 37 de la Ley 685 de 2001 será exequible siempre y cuando las autoridades del orden nacional acuerden con los entes territoriales las medidas de protección necesarias para salvaguardar el ambiente y la población del territorio.

En esta ocasión, la Sala Primera recalcó y aclaró que para que haya un acuerdo, tal como lo ha entendido la jurisprudencia de la Corte Constitucional ${ }^{63}$, debe adoptarse una decisión respaldada por la mayoría de las partes involucradas, lo que se aparta de lo regulado en el Decreto, que otorga la discrecionalidad al Ministerio de Minas y Energía para decidir unilateralmente sobre la adopción o no de las medidas de protección solicitadas por los entes territoriales.

11001032400020150016300, 25 de junio de 2015, consejero ponente Guillermo Vargas-Ayala. Disponible en: http://lamineria.com.co/lombia/wp-content/uploads/2015/07/suspensiondecreto-2691-de-2014.pdf

63 Corte Constitucional, Sentencia C-624-13, 11 de septiembre de 2013, magistrado ponente Jorge Ignacio Pretelt Chaljub. Disponible en: http://www.corteconstitucional.gov.co/ relatoria/2013/C-624-13.htm 
Según las consideraciones del Consejo de Estado, el Decreto 2691 de 2014 vulnera el principio de la autonomía de las entidades territoriales, ya que no les otorga una participación activa y eficaz en el proceso de autorización del desarrollo de proyectos mineros, pese a las serias consecuencias ambientales, sociales, culturales y económicas que esto conlleva para la vida local.

\section{E. La acción de los entes territoriales y sus ciudadanos}

La restricción o exclusión de la actividad minera se ha abierto paso con acuerdos expedidos por las entidades territoriales, mediante los cuales han pretendido tomar importantes determinaciones relacionadas con la minería en sus territorios y su protección ambiental, social, económica y cultural; sin embargo, tal como se ha expuesto, la regulación de estos temas mediante acuerdos municipales u ordenanzas departamentales ha suscitado controversia y, en algunos casos, se ha considerado que la regulación acerca de áreas excluidas y restringidas de la minería no corresponde a autoridades de orden municipal ni regional.

Un caso concreto se observa en la providencia emitida el 19 de abril de 2013 por el Tribunal Administrativo de Antioquia, acerca de la validez del contenido del Acuerdo 9 del 23 de noviembre de 2012, expedido por el Concejo Municipal de Jardín, Antioquia, por medio del cual pretendió restringir el desarrollo de actividades mineras en el municipio, con el fin de proteger su patrimonio cultural y ecológico, por lo que el demandante señaló la existencia de una extralimitación en las funciones del Concejo Municipal debido a que hay otra autoridad con esa competencia y a que se está decidiendo sobre un asunto de interés nacional, de bienes de propiedad estatal y que excede el ámbito territorial del municipio ${ }^{64}$.

En esta ocasión, el Tribunal consideró que al establecer prohibiciones que corresponden a la competencia de otras autoridades, el Acuerdo demandado es una manifestación de la extralimitación de las funciones del Concejo Municipal y aclaró que el Código de Minas permite restringir las actividades mineras en el perímetro urbano ${ }^{65}$, mas

\footnotetext{
64 Tribunal Administrativo de Antioquia, Sentencia 061 de 2013, magistrada ponente Beatriz Elena Jaramillo-Muñoz, 2013.

65 Ley 685 de 2001, por la cual se expide el Código de Minas [CM] y se dictan otras disposiciones,
} 
no prohibirlas en su totalidad como lo hace el Acuerdo; además resalta que con respecto a la exclusión de zonas de la actividad minera para la protección de recursos naturales renovables y de medio ambiente, la autoridad ambiental es la competente y no el Concejo Municipal, y que la facultad de regular el uso del suelo por parte de las entidades territoriales no es absoluto, pues hay una norma de carácter especial que debe aplicarse en materia minera, el Código de Minas de 2001; por lo tanto, el Tribunal Administrativo de Antioquia declaró inválido el Acuerdo Municipal por contrariar el Código de Minas ${ }^{66}$.

Así mismo, se han declarado inválidos varios acuerdos municipales relacionados con el control de la industria minera, tal como se evidencia en la siguiente tabla:

\begin{tabular}{|c|c|c|c|c|}
\hline Municipio & Acuerdo & $\begin{array}{c}\text { Fecha y } \\
\text { fundamento de la } \\
\text { invalidación }\end{array}$ & $\begin{array}{c}\text { Sala de Tribunal } \\
\text { Superior de } \\
\text { Antioquia }\end{array}$ & Magistrado(a) \\
\hline Támesis & 008 de $31 / 8 / 12$ & $\begin{array}{c}6 / 02 / 13 \\
\text { Vicios de forma }\end{array}$ & $\begin{array}{c}\text { Sala Segunda de } \\
\text { Oralidad }\end{array}$ & $\begin{array}{c}\text { Gonzalo } \\
\text { Zambrano- } \\
\text { Velandia }\end{array}$ \\
\hline El Jardín & 009 de $23 / 11 / 12$ & $\begin{array}{c}19 / 04 / 13 \\
\text { Exceder } \\
\text { competencias }\end{array}$ & $\begin{array}{c}\text { Sala Segunda de } \\
\text { Oralidad }\end{array}$ & $\begin{array}{c}\text { Beatriz Elena } \\
\text { Jaramillo- } \\
\text { Muñoz }\end{array}$ \\
\hline Urrao & 020 de $22 / 11 / 12$ & $\begin{array}{c}10 / 05 / 13 \\
\text { Exceder } \\
\text { competencias }\end{array}$ & $\begin{array}{c}\text { Sala Primera de } \\
\text { Oralidad }\end{array}$ & $\begin{array}{c}\text { Yolanda } \\
\text { Obando-Montes }\end{array}$ \\
\hline Caicedo & 003 de $15 / 02 / 13$ & $\begin{array}{c}30 / 05 / 13 \\
\text { Exceder } \\
\text { competencias }\end{array}$ & $\begin{array}{c}\text { Sala Primera de } \\
\text { Oralidad }\end{array}$ & $\begin{array}{c}\text { Yolanda } \\
\text { Obando-Montes }\end{array}$ \\
\hline Cañasgordas & 024 de $28 / 11 / 12$ & $\begin{array}{c}\text { Exceder } \\
\text { competencias }\end{array}$ & $\begin{array}{c}\text { Sala Primera de } \\
\text { Oralidad }\end{array}$ & $\begin{array}{c}\text { Álvaro Cruz- } \\
\text { Riaño }\end{array}$ \\
\hline
\end{tabular}

\section{Tabla 1}

\section{Acuerdos Municipales declarados sin validez por el Tri- bunal Administrativo de Antioquia.}

Fuente: tomado de Fernando Vargas-Valencia, Presentación sobre Legalidad de Acuerdos Municipales en torno a la prohibición de la minería, Támesis, Antioquia, 27 de agosto de 2014.

15 de agosto de 2001, 44.545 Diario Oficial, 8 de septiembre de 2001, art. 35. Disponible en: http://www.secretariasenado.gov.co/senado/basedoc/ley_0685_2001.html

66 Tribunal Administrativo de Antioquia, Sentencia 061 de 2013, magistrada ponente Beatriz Elena Jaramillo-Muñoz, 2013. 
Por otro lado, no se puede olvidar que, de conformidad con la jurisprudencia ${ }^{67}$, las entidades territoriales tienen el derecho y el deber de participar activamente en la adopción de decisiones relacionadas con la industria minera; sin embargo según las decisiones judiciales emitidas al respecto hasta el momento, resulta improcedente la realización de Acuerdos Municipales que excluyen áreas no urbanas de la actividad minera en sus municipios cuando no media un acuerdo con las autoridades ambientales y mineras.

Sin embargo, en la actualidad no hay claridad sobre la legalidad de este tipo de determinaciones teniendo en cuenta que el Decreto 934 de 2013 que prohíbe hacerlo de manera directa fue suspendido de manera provisional.

\section{F. Límites que puede interponer el constituyente primario}

La Ley 136 de $1994{ }^{68}$ por medio de la cual se dictaron normas para modernizar la organización y el funcionamiento de los municipios estableció:

Artículo 33. Usos del suelo. Cuando el desarrollo de proyectos de naturaleza turística, minera o de otro tipo, amenace con crear un cambio significativo en el uso del suelo, que dé lugar a una transformación en las actividades tradicionales de un municipio, se deberá realizar una consulta popular de conformidad con la ley. La responsabilidad de estas consultas estará a cargo del respectivo municipio.

Parágrafo. En todo caso, las decisiones sobre el uso del suelo deben ser aprobadas por el Concejo Municipal ${ }^{69}$.

Según el contenido de esta norma, en los municipios deberán adelantarse consultas populares para decidir sobre el desarrollo

67 Corte Constitucional, Sentencia C-123-14, 5 de marzo de 2014, magistrado ponente Alberto Rojas-Ríos, demanda de inconstitucionalidad contra el artículo 37 de la Ley 685 de 2001 y del artículo 2 (parcial) del Decreto 0934 de 2013, expediente D-9700. Disponible en: http:// www.corteconstitucional.gov.co/relatoria/2014/c-123-14.htm

68 Ley 136 de 1994, por medio de la cual se dictaron normas para modernizar la organización y el funcionamiento de los municipios, reglamentada parcialmente por el Decreto Nacional 863 de 2009, 41.377 Diario Oficial, 2 de junio de 1994. Disponible en: http://www.secretariasenado. gov.co/senado/basedoc/ley_0136_1994.html

69 Ley 136 de 1994, por medio de la cual se dictaron normas para modernizar la organización y el funcionamiento de los municipios, reglamentada parcialmente por el Decreto Nacional 
de proyectos con potencialidad de cambiar el uso del suelo y las actividades tradicionales del municipio. La Ley 134 de $1994^{70}$ define la consulta popular de la siguiente manera:

Artículo 8. Consulta popular. La consulta popular es la institución mediante la cual, una pregunta de carácter general sobre un asunto de trascendencia nacional, departamental, municipal, distrital o local, es sometido por el presidente de la República, el gobernador o el alcalde, según el caso, a consideración del pueblo para que este se pronuncie formalmente al respecto.

En todos los casos, la decisión del pueblo es obligatoria ${ }^{71}$.

Según lo dispuesto en la Ley 134 de 1994, las preguntas que se formulen en desarrollo de la consulta popular deben ser claras y cerradas, de manera que las opciones de respuesta sean "sí" o "no"72. Así mismo, el alcalde deberá presentar las preguntas que forman parte de la consulta junto con su justificación ante el Concejo Municipal para la respectiva aprobación y concepto favorable acerca de su conveniencia, para lo que el Concejo contará con un término de veinte (20) días, prorrogables por diez (10) días más; posteriormente, la consulta se remitirá al Tribunal Contencioso Administrativo competente para que emita su pronunciamiento de constitucionalidad dentro del término de 15 días $^{73}$.

De acuerdo con lo anterior, para llevar a cabo la consulta se deberá obtener este concepto previo del Concejo Municipal y la declaración de constitucionalidad del contenido de la consulta por parte del órgano judicial competente. Una vez se surta lo anterior, la consulta deberá realizarse dentro de los dos meses siguientes a

863 de 2009, 41.377 Diario Oficial, 2 de junio de 1994, artículo 33. Disponible en: http://www. secretariasenado.gov.co/senado/basedoc/ley_0136_1994.html

70 Ley 134 de 1994, por la cual se dictan normas sobre mecanismos de participación ciudadana, 41.373 Diario Oficial, 31 de mayo de 1994. Disponible en: http://www.secretariasenado.gov. co/senado/basedoc/ley_0134_1994.html

71 Ley 134 de 1994, por la cual se dictan normas sobre mecanismos de participación ciudadana, 41.373 Diario Oficial, 31 de mayo de 1994, artículo 8. Disponible en: http://www.secretaria senado.gov.co/senado/basedoc/ley_0134_1994.html

72 Ley 134 de 1994, por la cual se dictan normas sobre mecanismos de participación ciudadana, 41.373 Diario Oficial, 31 de mayo de 1994, artículo 52. Disponible en: http://www.secretaria senado.gov.co/senado/basedoc/ley_0134_1994.html

73 Ley 134 de 1994, por la cual se dictan normas sobre mecanismos de participación ciudadana, 41.373 Diario Oficial, 31 de mayo de 1994, artículo 53. Disponible en: http://www.secretaria senado.gov.co/senado/basedoc/ley_0134_1994.html 
la emisión de estos pronunciamientos ${ }^{74}$. Finalmente, la decisión que tome el pueblo tendrá fuerza vinculante por lo que será de obligatorio cumplimiento, siempre y cuando la decisión alcance una votación de la mitad más uno y haya participado más de la tercera parte de la población apta para sufragar ${ }^{75}$.

El desarrollo de este mecanismo de participación cobró relevancia para el tema minero a partir de la Consulta Popular adelantada el 28 de julio de 2013 en el municipio de Piedras (departamento de Tolima), convocada por el alcalde de este ente territorial, mediante la cual la población del municipio manifestó su inconformidad frente al desarrollo de actividades mineras para la extracción de oro, y dijo no a la minería en este municipio ${ }^{76}$. El texto que se sometió a consideración de los habitantes del municipio fue:

Está de acuerdo, como habitante del municipio de Piedra Tolima que se realice en nuestra jurisdicción (sic) actividades de exploración, explotación, tratamiento, transformación, transporte, lavado de materiales provenientes de las actividades de explotación minera aurífera a gran escala, almacenamiento y el empleo de materiales nocivos para la salud y el medio ambiente, de manera específica el cianuro ylo cualquier otra sustancia o material peligroso asociado a dichas actividades y se utilicen las aguas superficiales y subterráneas de nuestro municipio en dichos desarrollos o en cualquier otro de naturaleza similar que pueda afectar y/o limitar el abastecimiento de agua potable para el consumo humano, la vocación productiva tradicional y agrícola de nuestro municipio. $\mathrm{NO}$ SÍ

El Tribunal Administrativo del Tolima, mediante sentencia del 26 de junio de 2013, declaró que el texto que se sometería a consulta popular estaba ajustado a la Constitución y a la Ley. La empresa Anglogold Ashanti Colombia S.A. solicitó la nulidad sobre esta providencia; sin embargo, el Tribunal rechazó esta solicitud por improcedente.

74 Ley 134 de 1994, por la cual se dictan normas sobre mecanismos de participación ciudadana, 41.373 Diario Oficial, 31 de mayo de 1994, artículo 54. Disponible en: http://www.secretaria senado.gov.co/senado/basedoc/ley_0134_1994.html

75 Ley 134 de 1994, por la cual se dictan normas sobre mecanismos de participación ciudadana, 41.373 Diario Oficial, 31 de mayo de 1994, artículo 55. Disponible en: http://www.secretaria senado.gov.co/senado/basedoc/ley_0134_1994.html

76 Angélica María Cuevas-Guarnizo, Hace un año Piedras le dijo no a la minería: ¿de qué sirvió?, El Espectador, 25 de agosto de 2014. Disponible en: 2014 de http://www.elespectador.com/ noticias/nacional/hace-un-ano-piedras-le-dijo-no-mineria-de-sirvio-articulo-512776 
Como consecuencia de lo anterior, la empresa minera presentó una acción de tutela ante el Consejo de Estado, en contra del Tribunal Administrativo del Tolima, con el argumento de que con las decisiones adoptadas por este Tribunal se vulneraron los derechos fundamentales a la defensa, al debido proceso y de la buena fe en cabeza de la mencionada sociedad, al no habérsele vinculado en el trámite de la consulta popular, aunque contaba con los permisos y licencias necesarias para adelantar la actividad minera en el municipio.

Así mismo, la empresa accionante argumentó que las autoridades municipales carecen de competencia para excluir la zona de la actividad minera, que el texto sometido a consulta popular carecía de imparcialidad, claridad y lealtad, y que se desconoció el principio de confianza legítima, debido a que la empresa ejercía la actividad minera con los permisos y licencias emitidos por las autoridades competentes. Por estas razones, Anglogold Ashanti solicitó dejar sin efecto las providencias emitidas por el Tribunal Administrativo del Tolima.

El pasado 21 de agosto de 2014, la Sección Cuarta de la Sala de lo Contencioso Administrativo del Consejo de Estado emitió su pronunciamiento respecto de la tutela instaurada y negó las pretensiones de la parte actora. En esta ocasión, el Despacho consideró que en el trámite de la consulta popular que se adelantó en el municipio de Piedras, Tolima, no hubo vulneración a los derechos fundamentales invocados, teniendo en cuenta que el procedimiento se ajustó a la Ley y a la CPC, pues dentro del proceso establecido para adelantar las consultas populares no están consagradas la necesidad de citar a terceros con interés en el asunto, ni la posibilidad de que personas jurídicas o naturales se opongan al ejercicio de un derecho de rango constitucional, como la participación ciudadana manifestada por medio de una consulta popular ${ }^{77}$.

De igual manera, se adelantó otra consulta popular en el municipio de Tauramena, (departamento de Casanare) en desarrollo de la cual la población del municipio se pronunció contundente-

77 Consejo de Estado, Sala de lo Contencioso Administrativo, Sección Cuarta, Proceso 1100103-15-000-2013-02635-00, 21 de agosto de 2014, consejero ponente Carmen Teresa Ortiz de Rodríguez. Disponible en: http://190.24.134.67/documentos/boletines/153/AC/11001-03-15000-2013-02635-00(AC).pdf 
mente en contra del desarrollo de actividades petroleras, pues de 4.598 votos válidos registrados, 4.426 fueron por el "No" y 151 fueron por el "Sí"78. Esta decisión fue adoptada por el Concejo Municipal de Tauramena mediante Acuerdo 006 del 10 de marzo de 2014. Igualmente, el concejo municipal de Onzaga, Santander, ha adoptado la decisión de adelantar una consulta popular para que los ciudadanos del municipio decidan sobre las actividades de minería y explotación de hidrocarburos que se pretende adelantar en el territorio municipal en el marco de la situación de conflictividad por el recurso hídrico que atraviesa la zona ${ }^{79}$.

En Perú, por ejemplo, estas consultas son conocidas como consultas vecinales y también se han utilizado como un mecanismo para excluir territorios de la actividad minera. Uno de los casos más reconocidos en Perú es la consulta vecinal en la Serranía del departamento de Piura, instituida mediante ordenanza municipal y enfocada a la protección del agua, los páramos, la biodiversidad y el patrimonio comunal, frente a la actividad minera. En este caso, el organismo electoral se pronunció en el sentido de que esa consulta vecinal constituye: “...un atentado contra el sistema democrático y ha ordenado a su procurador denunciar a los alcaldes por una supuesta "usurpación de funciones" $"$ " En la misma discusión está el caso del proyecto minero Conga en Cajamarca, Perú, en contra del cual se pretende ejercer el derecho a la participación del pueblo mediante una consulta promovida por el presidente regional, quien ha recibido posiciones en contra que afirman que esa conducta vulnera la ley y la Constitución Política peruana ${ }^{81}$, y que involucra competencias que no le corresponden al gobierno local ${ }^{82}$.

78 Registraduría Nacional del Estado Civil, En consulta popular celebrada ayer domingo 15 de diciembre, los habitantes de Tauramena, Casanare, dijeron "no" a la explotación de hidrocarburos, 120 ciudadanos prestaron su servicio como jurados de votación, comunicado de prensa 1029 de 2013, domingo 15 de diciembre de 2013. Disponible en: http://www.registraduria.gov. co/En-consulta-popular-celebrada-hoy,12424.html

79 Equipo Jurídico Pueblos, EJP, Consulta Popular sobre la Gran Minería en Onzaga, Santander, sábado 16 de agosto de 2014. Disponible en: http://derechodelpueblo.blogspot.com.co/2014/08/ consulta-popular-sobre-la-gran-mineria.html

80 Hildebrando Castro Pozo-Díaz, ¿Pueden las municipalidades convocar una consulta vecinal? (Asociación Servicios Educativos Rurales (SER), Perú, 2007). Disponible en: http://alainet. org/active/19626\&lang=es

81 Perú, Constitución Política, 29 de diciembre de 1993. Disponible en: http://www.wipo.int/ wipolex/es/details.jsp?id=6544

82 RPP Noticias, García-Toma: Hacer referéndum en Cajamarca es ir contra la ley. En caso que insista en realizar el referéndum, precisó que Gregorio Santos podría ser denunciado, domingo 
Volviendo al caso colombiano, la controversia también ha girado en torno a la facultad que tienen los alcaldes y los gobernadores de convocar consultas populares sobre un asunto minero, pues se argumenta que el único que tiene esta competencia es el presidente de la República. Por esta razón, la Procuraduría Provincial de Ibagué anunció el inicio de procesos disciplinarios a los alcaldes que han promovido estas consultas por extralimitación en sus funciones ${ }^{83}$. Sin embargo, hasta el momento, no se ha emitido ninguna decisión y el tema sigue siendo objeto de discusión, pues la Sentencia C-12314 y los pronunciamientos del Consejo de Estado no han tratado claramente el ejercicio de la consulta popular promovida por los alcaldes en virtud de un deber establecido por el artículo 33 de la Ley 136 de 1994, y además se debe tener en cuenta que en este caso los ciudadanos (el pueblo) son los que deciden, no el funcionario público.

En este sentido, cabe resaltar que el Código Disciplinario Único ${ }^{84}$ establece que el proceso disciplinario debe regirse, entre otros, por los principios de legalidad ${ }^{85}$, culpabilidad ${ }^{86}$ y antijuricidad $^{87}$; sin embargo, no es claro cómo en el caso de las consultas populares convocadas por los alcaldes para excluir las actividades mineras y petroleras en sus municipios puede configurarse la antijuricidad de la conducta, pues al respecto dispone el Código Disciplinario: "La falta será antijurídica cuando afecte el deber funcional sin justificación alguna"88.

10 de febrero de 2013 (Perú). Disponible en: http://www.rpp.com.pe/2013-02-10-garcia-toma -hacer-referendum-en-cajamarca-es-ir-contra-la-ley-noticia_566048.html

83 Ramiro Gálvez-Aldana, Alcance de las consultas populares en Colombia (Universidad de Tolima, Ibagué, 30 de abril de 2014). Disponible en: http://comiteambiental.ut.edu.co/index. php/consultas-populares

84 Ley 734 de 2002, por la cual se expide el Código Disciplinario Único, 44.708 Diario Oficial, 13 de febrero de 2002. Disponible en: http://www.secretariasenado.gov.co/senado/basedoc/ ley_0734_2002.html

85 Ley 734 de 2002, por la cual se expide el Código Disciplinario Único, 44.708 Diario Oficial, 13 de febrero de 2002. Disponible en: http://www.secretariasenado.gov.co/senado/basedoc/ ley_0734_2002.html. "Artículo 4. Legalidad. El servidor público y el particular en los casos previstos en este código solo serán investigados y sancionados disciplinariamente por comportamientos que estén descritos como falta en la ley vigente al momento de su realización".

86 Artículo 13. Culpabilidad. En materia disciplinaria queda proscrita toda forma de responsabilidad objetiva. Las faltas solo son sancionables a título de dolo o culpa.

87 Artículo 5. Ilicitud sustancial. La falta será antijurídica cuando afecte el deber funcional sin justificación alguna.

88 Ley 734 de 2002, por la cual se expide el Código Disciplinario Único, 44.708 Diario Oficial, 13 de febrero de 2002, artículo 5. Disponible en: http://www.secretariasenado.gov.co/senado/ basedoc/ley_0734_2002.html 
Según la Corte Constitucional, el quebrantamiento del deber funcional involucra el "desconocimiento de la función social que le incumbe al servidor público o al particular que cumple funciones públicas" "89; así mismo, con respecto al contenido de ese deber funcional, la Corte ha precisado que se encuentra integrado por:

...(i) el cumplimiento estricto de las funciones propias del cargo, (ii) la obligación de actuar acorde a la Constitución y a la ley; (iii) garantizando una adecuada representación del Estado en el cumplimiento de los deberes funcionales ${ }^{90}$.

Como se ha mencionado, la convocatoria de una consulta popular constituye un deber de los alcaldes en virtud de lo dispuesto por el artículo 33 de la Ley 136 de 1994, según el cual cuando un proyecto minero tenga la capacidad de ocasionar un cambio importante en el uso del suelo, que pueda transformar las actividades tradicionales de los habitantes del municipio, el municipio deberá velar por la realización de una consulta popular al respecto ${ }^{91}$. Así las cosas, tampoco se puede hablar de una extralimitación en las funciones de los alcaldes, pues se está actuando en ejercicio de un deber legal.

Por otro lado, el Código Disciplinario Único dispone que estará exento de la acción disciplinaria, el que realice la conducta en estricto cumplimiento de un deber constitucional o legal de mayor importancia que el sacrificado o por salvar un derecho al cual deba ceder el cumplimiento del deber, en razón de la necesidad, adecuación, proporcionalidad y razonabilidad ${ }^{92}$. Por eso, en este caso, podrían configurarse estas causales de exclusión de responsabilidad, teniendo en cuenta que se sustenta en un deber legal e, incluso, constitucional, si se tiene en cuenta que se encuentran

89 Corte Constitucional, Sentencia C-373-02, 15 de mayo de 2002, magistrado ponente Jaime Córdoba-Triviño. Disponible en: http://www.corteconstitucional.gov.co/relatoria/2002/c-373-02. htm

90 Corte Constitucional, Sentencia C-819-06, 4 de octubre de 2006, magistrado ponente Jaime Córdoba-Triviño. Disponible en: http://www.corteconstitucional.gov.co/relatoria/2006/c-819-06. htm

91 Ley 136 de 1994, por medio de la cual se dictaron normas para modernizar la organización y el funcionamiento de los municipios, reglamentada parcialmente por el Decreto Nacional 863 de 2009, 41.377 Diario Oficial, 2 de junio de 1994. Disponible en: http://www.secretariasenado. gov.co/senado/basedoc/ley_0136_1994.html

92 Ley 734 de 2002, por la cual se expide el Código Disciplinario Único, 44.708 Diario Oficial, 13 de febrero de 2002, artículo 28. Disponible en: http://www.secretariasenado.gov.co/senado/ basedoc/ley_0734_2002.html 
involucrados los principios de sostenibilidad ambiental, participación ciudadana y protección del patrimonio cultural y natural, que resultan de gran trascendencia municipal y nacional.

Finalmente, de acuerdo con Allan R. Brewer-Carías, la manifestación del derecho a la democracia está condicionada por la distribución vertical del poder público, lo cual implica el proceso de descentralización política entre entidades autónomas, y esta descentralización permite el ejercicio de la democracia participativa y la posibilidad de controlar el poder central ${ }^{93}$.

93 Allan R. Brewer-Carías, Sobre las nuevas tendencias del derecho constitucional: del reconocimiento del derecho a la Constitución y del derecho a la democracia, 119 Vniversitas, 93-112 (julio-diciembre de 2009). Disponible en: http://www.scielo.org.co/pdf/vniv/n119/n119a10.pdf 


\section{CONCLUSIóN}

Dado el auge de las actividades mineras en el país, es innegable el impacto económico, social, ambiental y cultural que puede traer en la vida de las comunidades locales, por lo que se hace cada vez más necesario que las autoridades territoriales cuenten con una activa y eficaz participación en las decisiones que llevan a la autorización de la actividad en su jurisdicción, teniendo en cuenta que son estos entes locales los que deberán lidiar directamente con las consecuencias negativas de esta actividad en su jurisdicción territorial.

Resulta fundamental reconocer que además de la propiedad estatal sobre el subsuelo y los recursos naturales no renovables y la categorización de interés público de la actividad minera, hay derechos, postulados y principios que deben ser considerados antes de adoptar decisiones basadas únicamente en el desarrollo económico, como el derecho a un ambiente sano, al agua, a la salud, a la soberanía alimentaria y a la participación, en concordancia con el principio de autonomía territorial y descentralización.

Es un deber de las autoridades territoriales participar en las decisiones que, en sede de las autoridades nacionales, llevan a autorizar el desarrollo de proyectos en sus territorios, más aún cuando hay funciones y deberes a su cargo, relacionados con el ordenamiento del uso del suelo, la preservación de los recursos naturales y la protección de los derechos fundamentales de las personas.

Por otro lado, queda abierta la discusión sobre la competencia de los alcaldes y los gobernadores para convocar consultas populares relacionadas con la restricción o exclusión de zonas locales para la minería, dado que algunos consideran que esta competencia únicamente es del presidente de la República, dada la connotación de propiedad nacional que tienen los recursos minerales. Sin embargo, según lo dispuesto en el artículo 33 de la Ley 136 de 1994, y en consonancia con los principios de participación ciudadana, conservación ambiental y autonomía territorial, es un deber de los alcaldes y gobernadores convocar a consulta popular y participar activamente en la adopción de este tipo de decisiones. 


\section{BIBLIOGRAFÍA}

\section{Libros}

Colombia, Ministerio de Minas y Petróleos, Estatuto minero (Empresa Colombiana de Minas, Bogotá, 1970).

Garay, Luis, dir.; Cabrera-Leal, Mauricio; Espitia-Zamora，Jorge Enrique; Fierro-Morales, Julio; Negrete-Montes, Rodrigo E.; Pardo-Becerra, Luis Álvaro; Rudas-Lleras, Guillermo \& Vargas-Valencia, Fernando, Minería en Colombia: derechos, políticas públicas y gobernanza (Contraloría General de la República, Bogotá, 2013 ). Disponible en: http://www.contraloria.gov.co/ documents/10136/182119332/Libro_mineria_sep3_2013.pdf/65bf77a0-8b0b-430a9726-dad0e72639c6

Rodríguez, Gloria Amparo \& Muñoz, Lina Marcela, La participación en la gestión ambiental: un reto para el nuevo milenio (Universidad del Rosario, Bogotá, 2009). Disponible en: http://philpapers.org/archive/RODLPE.pdf

\section{Colaboraciones en obras colectivas}

Cabrera-Leal, Mauricio \& Fierro-Morales, Julio, Implicaciones ambientales y sociales del modelo extractivista en Colombia, en Minería en Colombia: Derechos, políticas públicas y gobernanza, 89-124 (Luis Jorge GaraY-SALAmanca, dir., Contraloría General de la República, Bogotá, 2013 ). Disponible en: http://www.contraloria. gov.co/documents/10136/182119332/Libro_mineria_sep3_2013.pdf/65bf77a08b0b-430a-9726-dad0e72639c6

Negrete-Montes, Rodrigo E., Derechos, minería y conflictos. Aspectos normativos, en Minería en Colombia: derechos, politicas públicas y gobernanza, 281-338 (LuIs Jorge Garay-Salamanca, dir., Contraloría General de la República, Bogotá, 2013 ). Disponible en: http://www.contraloria.gov.co/documents/10136/182119332/ Libro_mineria_sep3_2013.pdf/65bf77a0-8b0b-430a-9726-dad0e72639c6

Pardo-Becerra, Luis Álvaro, Propuestas para recuperar la gobernanza del sector minero colombiano, en Minería en Colombia: Derechos, políticas públicas y gobernanza, 177-211 (Luis Jorge Garay-Salamanca, dir., Contraloría General de la República, Bogotá, 2013 ). Disponible en: http://www.contraloria.gov.co/ documents/10136/182119332/Libro_mineria_sep3_2013.pdf/65bf77a0-8b0b-430a9726-dad0e72639c6

\section{Revistas}

Brewer-Carías, Allan R., Sobre las nuevas tendencias del derecho constitucional: del reconocimiento del derecho a la Constitución y del derecho a la democracia, 119 Vniversitas, 93-112 (julio-diciembre de 2009). Disponible en: http://www.scielo. org.co/pdf/vniv/n119/n119a10.pdf

Wilches-Durán, Rafael E., Principio ambiental de precaución y contratación mercantil 
en derecho colombiano. Planteamiento del problema, 123 Vniversitas, 283-314 (2011). Disponible en: http://vniversitasjuridica.javeriana.edu.co/descargas. php?archivo $=$ Universitas $-123 \% 20-\% 209$. pdf\&idArt $=313 \&$ edicion $=123$

\section{Tratados internacionales}

Convención Relativa a los Humedales de Importancia Internacional especialmente como Hábitat de Aves Acuáticas o Convenio de Ramsar, Ramsar (Irán), 18 de enero de 1971, en vigor: 21 de diciembre de 1975. Disponible en: http://www.ramsar.org/es

Organización Internacional del Trabajo, OIT, Convenio 169 sobre pueblos indígenas y tribales en países independientes, adoptado por la 76 reunión de la Conferencia General de la Organización Internacional del Trabajo, OIT, Ginebra 1989. Disponible en: http://www.ilo.org/wcmsp5/groups/public/---ed_norm/---normes/ documents/publication/wcms_100910.pdf

\section{Normatividad internacional}

Perú, Constitución Política, 29 de diciembre de 1993. Disponible en: http://www.wipo. int/wipolex/es/details.jsp?id=6544

\section{Normatividad colombiana}

Constitución Política [Const], 7 de julio de 1991. Versión corregida, 116 Gaceta Constitucional, 20 de julio de 1991, disponible en: http://www.secretariasenado. gov.co/senado/basedoc/constitucion_politica_1991.html

Decreto 330 de 2007, por el cual se reglamentan las audiencias públicas ambientales y se deroga el Decreto 2762 de 2005, 46.536 Diario Oficial, 8 de febrero de 2007. Disponible en: http://www.alcaldiabogota.gov.co/sisjur/normas/Norma1. jsp?i $=22974$

Decreto 863 de 2009, por el cual se reglamenta parcialmente la Ley 136 de 1994, 47.293 Diario Oficial, 16 de marzo de 2009. Disponible en: http://www.alcaldiabogota. gov.co/sisjur/normas/Norma1.jsp?i=35606

Decreto 934 de 2013, por el cual se reglamentan el artículo 37 de la Ley 685 de 2001, 48.785 Diario Oficial, 9 de mayo de 2013. Disponible en: http://www.alcaldiabogota.gov. co/sisjur/normas/Norma1.jsp?i=53052

Decreto 2691 de 2014, por el cual se reglamenta el artículo 37 de la Ley 685 de 2001 y se definen los mecanismos para acordar con las autoridades territoriales las medidas necesarias para la protección del ambiente sano, y en especial, de sus cuencas hídricas, el desarrollo económico, social, cultural de sus comunidades y la salubridad de la población, en desarrollo del proceso de autorización de actividades de exploración y explotación minera, 49.374 Diario Oficial, 23 de diciembre de 2014. Disponible en: http://www.alcaldiabogota.gov.co/sisjur/ normas/Norma1.jsp?i=60227

Ley 21 de 1991, por medio de la cual se aprueba el Convenio 169 sobre pueblos indígenas 
y tribales en países independientes, adoptado por la 76 reunión de la Conferencia General de la Organización Internacional del Trabajo, OIT, Ginebra 1989, 39.720 Diario Oficial, 6 de marzo de 1991. Disponible en: http://www.alcaldiabogota. gov.co/sisjur/normas/Norma1.jsp?i=37032

Ley 99 de 1993, por la cual se crea el Ministerio del Medio Ambiente, se reordena el Sector Público encargado de la gestión y conservación del medio ambiente y los recursos naturales renovables, se organiza el Sistema Nacional Ambiental, SINA y se dictan otras disposiciones, 41.146 Diario Oficial, 22 de diciembre de 1993. Disponible en: http://www.secretariasenado.gov.co/senado/basedoc/ ley_0099_1993.html

Ley 134 de 1994, por la cual se dictan normas sobre mecanismos de participación ciudadana, 41.373 Diario Oficial, 31 de mayo de 1994. Disponible en: http://www. secretariasenado.gov.co/senado/basedoc/ley_0134_1994.html

Ley 136 de 1994, por medio de la cual se dictaron normas para modernizar la organización y el funcionamiento de los municipios, reglamentada parcialmente por el Decreto Nacional 863 de 2009, 41.377 Diario Oficial, 2 de junio de 1994. Disponible en: http://www.secretariasenado.gov.co/senado/basedoc/ley_0136_1994.html

Ley 472 de 1998, por la cual se desarrolla el artículo 88 de la Constitución Política de Colombia en relación con el ejercicio de las acciones populares y de grupo y se dictan otras disposiciones, 43.357 Diario Oficial, 6 de agosto de 1998. Disponible en: http://www.secretariasenado.gov.co/senado/basedoc/ley_0472_1998.html

Ley 489 de 1998, por la cual se dictan normas sobre la organización y funcionamiento de las entidades del orden nacional, se expiden las disposiciones, principios y reglas generales para el ejercicio de las atribuciones previstas en los numerales 15 y 16 del artículo 189 de la Constitución Política y se dictan otras disposiciones, 43.464 Diario Oficial, 30 de diciembre de 1998. Disponible en: http://www. secretariasenado.gov.co/senado/basedoc/ley_0489_1998.html

Ley 685 de 2001, por la cual se expide el Código de Minas [CM] y se dictan otras disposiciones, 15 de agosto de 2001, 44.545 Diario Oficial, 8 de septiembre de 2001. Disponible en: http://www.secretariasenado.gov.co/senado/basedoc/ ley_0685_2001.html

Ley 734 de 2002, por la cual se expide el Código Disciplinario Único, 44.708 Diario Oficial, 13 de febrero de 2002. Disponible en: http://www.secretariasenado.gov. co/senado/basedoc/ley_0734_2002.html

Ley 1437 de 2011, por la cual se expide el Código de Procedimiento Administrativo y de lo Contencioso Administrativo, 47.956 Diario Oficial, 18 de enero de 2011. Disponible en: http://www.secretariasenado.gov.co/senado/basedoc/ ley_1437_2011.html

Ministerio de Minas y Energía, Concepto jurídico a los señores del Concejo Municipal de Yumbo en virtud de un derecho de petición de consulta, Radicado 20142180907-04-2014 (2014).

Ministerio de Minas y Energía, Concepto jurídico sobre solicitud de legalización minera en área ocupada por un área de reserva forestal, Radicado 2011060791 (2011). Disponible en: https://www.yumpu.com/es/document/view/14784859/2011060791ministerio-de-minas-y-energia 


\section{Jurisprudencia colombiana}

Consejo de Estado, Sala de lo Contencioso Administrativo, Sección Cuarta, Proceso 11001-03-15-000-2013-02635-00, 21 de agosto de 2014, consejero ponente Carmen Teresa Ortiz de Rodríguez. Disponible en: http://190.24.134.67/documentos/ boletines/153/AC/11001-03-15-000-2013-02635-00(AC).pdf

Consejo de Estado, Sala de lo Contencioso Administrativo, Sección Tercera, Proceso 73001-23-31-000-2002-00575-01, 29 de enero de 2004, consejero ponente Ramiro Saavedra-Becerra. Disponible en: http://juriscundi.cundinamarca.gov.co/public/ document/view/id/3072

Consejo de Estado, Sala de lo Contencioso Administrativo, Sección Tercera, Proceso 1100103260020130016200, 3 de septiembre de 2014, consejero ponente Hernán Andrade-Rincón. Disponible en: http://190.24.134.67/documentos/ sentencias/11001032600020130016200.pdf

Consejo de Estado, Sala de lo Contencioso Administrativo, Sección Primera, Proceso 11001032400020150016300, 25 de junio de 2015, consejero ponente Guillermo Vargas-Ayala. Disponible en: http://lamineria.com.co/lombia/wp-content/ uploads/2015/07/suspension-decreto-2691-de-2014.pdf

Corte Constitucional, Sentencia C-431-00, 12 de abril de 2000, magistrado ponente Vladimiro Naranjo-Mesa. Disponible en: http://www.corteconstitucional.gov. co/relatoria/2000/c-431-00.htm

Corte Constitucional, Sentencia C-339-02, 7 de mayo de 2002, Expediente D-3767, magistrado ponente Jaime Araújo-Rentería. Disponible en: http://www. corteconstitucional.gov.co/relatoria/2002/c-339-02.htm

Corte Constitucional, Sentencia C-373-02, 15 de mayo de 2002, magistrado ponente Jaime Córdoba-Triviño. Disponible en: http://www.corteconstitucional.gov.co/ relatoria/2002/c-373-02.htm

Corte Constitucional, Sentencia C-891-02, 22 de octubre de 2002, Expediente 4022, magistrado ponente Jaime Araújo-Rentería. Disponible en: http://www. corteconstitucional.gov.co/relatoria/2002/c-891-02.htm

Corte Constitucional, Sentencia C-819-06, 4 de octubre de 2006, magistrado ponente Jaime Córdoba-Triviño. Disponible en: http://www.corteconstitucional.gov.co/ relatoria/2006/c-819-06.htm

Corte Constitucional, Sentencia C-149-10, 4 de marzo de 2010, magistrado ponente Jorge Iván Palacio-Palacio. Disponible en: http://www.corteconstitucional.gov. co/relatoria/2010/c-149-10.htm

Corte Constitucional, Sentencia C-297-11, 27 de abril de 2011, magistrado ponente Juan Carlos Henao-Pérez. Disponible en: http://www.corteconstitucional.gov. co/relatoria/2011/c-297-11.htm

Corte Constitucional, Sentencia C-624-13, 11 de septiembre de 2013, magistrado ponente Jorge Ignacio Pretelt Chaljub. Disponible en: http://www.corteconstitucional. gov.co/relatoria/2013/C-624-13.htm

Corte Constitucional, Sentencia C-123-14, 5 de marzo de 2014, magistrado ponente Alberto Rojas-Ríos, demanda de inconstitucionalidad contra el artículo 
37 de la Ley 685 de 2001 y del artículo 2 (parcial) del Decreto 0934 de 2013, expediente D-9700. Disponible en: http://www.corteconstitucional.gov.co/ relatoria/2014/c-123-14.htm

Corte Constitucional, Sentencia T-760-07, 25 de septiembre de 2007, magistrado ponente Clara Inés Vargas-Hernández. Disponible en: http://www.corteconstitucional. gov.co/relatoria/2007/t-760-07.htm

Corte Constitucional, Sentencia T-348-12, 15 de mayo de 2012, magistrado ponente Jorge Ignacio Pretelt-Chaljub. Disponible en: http://www.corteconstitucional. gov.co/relatoria/2012/T-348-12.htm

Tribunal Administrativo de Antioquia, Sentencia 061 de 2013, magistrada ponente Beatriz Elena Jaramillo-Muñoz, 2013.

\section{Medios de comunicación y sitios web}

Castro Pozo-Díaz, Hildebrando, ¿Pueden las municipalidades convocar una consulta vecinal? (Asociación Servicios Educativos Rurales (SER), Perú, 2007). Disponible en: http://alainet.org/active/19626\&lang=es

Cuevas-Guarnizo, Angélica María, Hace un año Piedras le dijo no a la minería: ¿de qué sirvió?, El Espectador, 25 de agosto de 2014. Disponible en: 2014 de http://www. elespectador.com/noticias/nacional/hace-un-ano-piedras-le-dijo-no-mineriade-sirvio-articulo-512776

Equipo Jurídico Pueblos, EJP, Consulta Popular sobre la Gran Minería en Onzaga, Santander, sábado 16 de agosto de 2014. Disponible en: http://derechodelpueblo. blogspot.com.co/2014/08/consulta-popular-sobre-la-gran-mineria.html

Gálvez-Aldana, Ramiro, Alcance de las consultas populares en Colombia (Universidad de Tolima, Ibagué, 30 de abril de 2014). Disponible en: http://comiteambiental. ut.edu.co/index.php/consultas-populares

Ministerio de Minas y Energía, Glosario técnico minero (Bogotá, 2003). Disponible en: http://www.anm.gov.co/sites/default/files/DocumentosAnm/glosariominero.pdf

Procuraduría General de la Nación, Procuraduría Delegada para la Descentralización de las Entidades Territoriales, Descentralización y Entidades Territoriales (Instituto de Estudios del Ministerio Público, Bogotá, 2011). Disponible en: http://www. procuraduria.gov.co/portal/media/file/Cartilla $\% 20$ descentralizaci $\% \mathrm{C} 3 \% \mathrm{~B} 3 \mathrm{n}$.pdf

Registraduría Nacional del Estado Civil, En consulta popular celebrada ayer domingo 15 de diciembre, los habitantes de Tauramena, Casanare, dijeron "no" a la explotación de hidrocarburos, 120 ciudadanos prestaron su servicio como jurados de votación, comunicado de prensa 1029 de 2013, domingo 15 de diciembre de 2013. Disponible en: http://www.registraduria.gov.co/En-consulta-popularcelebrada-hoy, $12424 . h t m l$

RPP Noticias, García-Toma: Hacer referéndum en Cajamarca es ir contra la ley. En caso que insista en realizar el referéndum, precisó que Gregorio Santos podría ser denunciado, domingo 10 de febrero de 2013 (Perú). Disponible en: http://www. rpp.com.pe/2013-02-10-garcia-toma-hacer-referendum-en-cajamarca-es-ircontra-la-ley-noticia_566048.html 
Vargas-Valencia, Fernando, Presentación sobre Legalidad de Acuerdos Municipales en torno a la prohibición de la minería, Támesis, Antioquia, 27 de agosto de 2014. 